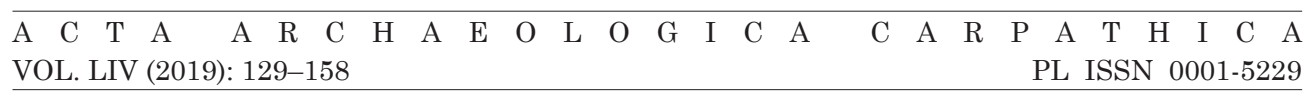

DOI 10.4467/00015229AAC.19.008.11885

\author{
ANDRZEJ KoKowski
}

\title{
„Erstes Ende” der Przeworsk-Kultur IM LUBLINERLAND
}

\section{The „FIRST END” Of Przeworsk CUlture IN THE LUBLIN REGION}

\begin{abstract}
The downfall of the settlement structure of Przeworsk culture in the Lublin region happened during chronological phases B2/C1-C1a. In course of the research concerning the time of formation of cemeteries, settlements and their duration of use, it was proved, that each of three settlement regions (north-western, western and eastern - see at the maps) displays certain unique features. Those differences are motivated by the accessibility of the Czerniczyn group in the preRoman period and the speed of Wielbark culture spread in the Roman period. The most long-term duration of the settlement was recorded in subregion I (A2-B2/C1-C1a). In subregion II it begins with phase B2 (possibly - end of phase B1) and lasts until the phase B2/C1-C1. In subregion III, after the episode of Przeworsk culture influx, that happened in the younger pre-Roman Period, Przeworsk culture appears in phases B2/C1-C1. The research of hoards of Roman coins allows us to suppose, that they were deposited in times of danger provoked by the migration of Goths in the years 193-218 A.D. (supposedly shortly after those events), as the latter date is indicated on the coin found in hoard from Spiczyn.
\end{abstract}

Keywords: Roman Period, Przeworsk culture, Goths, settlement, cemeteries, migrations, hoards of coins

Zusammenfassung: Während der Stufe B2/C1-C1a brachen die Siedlungsstrukturen der Przeworsk-Kultur in der Lublinerlandes zusammen. Bei der Untersuchung der Zeit der Errichtung von Gräberfelder und Siedlungen und der Dauer ihrer Nutzung wurde gezeigt, dass es in drei unterschiedlichen Subregionen (Nordwest, West und Ost - siehe Karten) grundlegende Unterschiede gibt. Sie haben Bedingungen, die durch die Zugänglichkeit der Gebiete bestimmt sind, die in der vorrömischen Eisenzeit von der Czarniczyn-Gruppe besetzt waren, und durch das Tempo der Wielbark-Kultur in der Römischen Kaiserzeit. Die am längsten andauernde Besiedlung fand in der Subregion I (A2-B2/C1-C1a) statt. In der Subregion II hat es einen Beginn zu Beginn der Stufe B2 (möglicherweise im späten B1) und dauerte bis zur Stufe B2/C1-C1. In der Subregion III tritt die Przeworsk-Kultur nach einer in die jüngere vorrömische Eisenzeit fallenden Episode

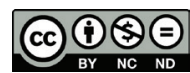

This is an open access article distributed under the terms of the Creative Commons license (CC BY-NC-ND 3.0 PL) 
der Durchdringung der Bevölkerung der Przeworsk-Kultur in den Stufen B2/C1-C1 auf. Bei der Untersuchung der Deponierung römischer Münzen können wir annehmen, dass sie, wahrscheinlich im Hinblick auf die Bedrohung durch die umherziehenden Goten, zwischen 193 und $218 \mathrm{n}$. Chr. (Wahrscheinlich kurz nach dieser Zeit) versteckt waren, da das jüngste Datum die jüngste Münze aus der Hortfund in Spiczyn angibt.

Stichworte: Römische Kaiserzeit, Przeworsk-Kultur, Gothen, Siedlungen, Gräberfelde, Migration, Münzschätze

\section{DER ANFANG}

Der zweideutig lautende Titel hat seine historische Logik, derer Wurzeln im Besiedlungsbild der Przeworsk-Kultur in dieser Region zu suchen sind. Alles spricht dafür, dass nach dem Zusammenbruch ihrer Strukturen in der mittleren Kaiserzeit (Stufe B2/C1-C1a), in der Spätkaiserzeit, zumindest im westlichen Teil des Lublinerlandes die Vertreter der Przeworsk-Kultur wieder auftauchen. Die Geschichte der zweiten Phase der Przeworsk-Besiedlung wird in diesem Band von Marta Stasiak-Cyran dargestellt, der Autorin von meisten Entdeckungen für die genannte These.

Die Besiedlung der Przeworsk-Kultur im Lublinerland, d.h. in der Lubliner Hochebene, der Kleinmasowien-Ebene im Norden, von Polesie Lubelskie im Nordosten bis zum Hügelland Roztocze im Süden, muss in drei separaten Subregionen betrachtet werden: I. in der nordwestlichen entlang der Weichsel bis zu den Flüssen Wieprz im Süden und Tyśmienica im Osten; II. in der westlichen, die die westliche Lubliner Hochebene zwischen Weichsel und Wieprz sowie die Kleinmasowien-Ebene (Lubartów-Ebene) umfasst; III. in der östlichen, östlich von Wieprz bis Bug mit der Südgrenze in Roztocze. Im nördlichen Teil der letztgenannten Subregion (IIIa) bis etwa dem Nordrand der Lubliner Hochebene fehlen bisher Spuren der Przeworsk-Besiedlung. In jeder Region sieht diese Besiedlung anders aus; die wichtigste Differenz liegt darin, wann die ersten Siedler der Przeworsk-Kultur auftauchen (Tabelle 1).

Im Aufsatz werden die Fundstellen, in denen archäologische Ausgrabungen durchgeführt wurden sowie die Zufallsfunde, deren Przeworsk-Charakter keine Zweifel erweckt, berücksichtigt. Die Funde aus Geländeübergehungen bleiben außer Acht, da ihre Kulturinterpretation und Datierung oft unsicher sind (vgl. E. Banasiewicz 1997b). „Erstes Ende“ der Przeworsk-Kultur beruht auf der Analyse von 59 Fundstellen (Liste I). Es bleibt die Frage, inwieweit die spärliche Anzahl von Fundstellen durch geringes Interesse an die Przeworsk-Kultur im Lublinerland verursacht ist und in welchem Grad unsere Schlüsse durch den unbefriedigenden Forschungsstand beeinflusst sind. 
Tabelle 1. Die Przeworsk-Kultur im Lublinerland (A2-C1)

\begin{tabular}{|c|c|c|c|c|c|c|c|c|c|c|}
\hline Nr. & Ort & A2 & A3 & $\mathrm{B} 1 \mathrm{a}$ & B1b & $\mathrm{B} 2 \mathrm{a}$ & $\mathrm{B} 2 \mathrm{~b}$ & $\mathrm{~B} 2 / \mathrm{C} 1$ & $\mathrm{C} 1 \mathrm{a}$ & $\mathrm{C} 1 \mathrm{~b}$ \\
\hline \multicolumn{11}{|c|}{ Subegion I. Nordwestliches Lublinerland } \\
\hline 1 & Brzeźce & $\mathbf{X}$ & & & & & & & & \\
\hline 2 & Drążgów 1 & $\mathbf{X}$ & $\mathbf{X}$ & $\mathbf{X}$ & $\mathbf{X}$ & $\mathbf{X}$ & $\mathbf{X}$ & $\mathbf{X}$ & & \\
\hline 4 & Masów & $\mathbf{X}$ & $\mathbf{X}$ & $\mathbf{X}$ & $\mathbf{X}$ & $\mathbf{X}$ & $\mathbf{X}$ & $\mathbf{X}$ & & \\
\hline 6 & Sobieszyn 1 & $\mathbf{X}$ & $\mathbf{X}$ & $\mathbf{X}$ & $\mathbf{X}$ & $\mathbf{X}$ & $\mathbf{X}$ & $\mathbf{X}$ & & \\
\hline 5 & Sobieszyn 14 & $\mathbf{X}$ & $\mathbf{X}$ & $\mathbf{X}$ & $\mathbf{X}$ & $\mathbf{X}$ & $\mathbf{X}$ & $\mathbf{X}$ & $\mathrm{X} ?$ & \\
\hline 3 & Drążgów 2-3 & & $\mathrm{X}$ & $\mathbf{X}$ & $\mathbf{X}$ & $\mathbf{x}$ & $\mathbf{X}$ & $\mathrm{X}$ & & \\
\hline 8 & Wola Skromowska & & & $\mathbf{X}$ & $\mathbf{X}$ & $\mathbf{x}$ & $\mathbf{X}$ & $\mathbf{X}$ & & \\
\hline 7 & Tarkawica & & & & & & & $\mathbf{X}$ & & \\
\hline 9 & Zawieprzyce & & & & & & & $\mathbf{X}$ & $\mathbf{X}$ & \\
\hline \multicolumn{11}{|c|}{ Subregion II. Westliches Lublinerland } \\
\hline 16 & Iłki & $\mathrm{X}$ & & & & & & & & \\
\hline 10 & Bliskowice & & & & & $\mathbf{x}$ & & & & \\
\hline 12 & Cynków & & & & & $\mathbf{X}$ & $\mathbf{X}$ & & & \\
\hline 18 & Kazimierz Dolny & & & & & $\mathbf{X}$ & $\mathbf{X}$ & & & \\
\hline 28 & Opole Lubelskie & & & & & $\mathbf{x}$ & $\mathbf{X}$ & & & \\
\hline 29 & Osówka & & & & & $\mathbf{X}$ & $\mathbf{X}$ & & & \\
\hline 32 & Szczekarków & & & & & $\mathbf{X}$ & $\mathbf{X}$ & & & \\
\hline 33 & Wrzelów & & & & & $\mathrm{X}$ & $\mathbf{X}$ & & & \\
\hline 20 & Lublin Ducha Strasse & & & & & $\mathrm{X} ?$ & $\mathrm{X} ?$ & & & \\
\hline 21 & Lublin-Hajdów & & & & & $\mathrm{X} ?$ & $\mathrm{X} ?$ & & & \\
\hline 23 & Lublin-Wola Sławińska & & & & & $\mathrm{X} ?$ & $\mathrm{X} ?$ & & & \\
\hline 11 & Chodel 28 & & & & & & $\mathbf{X}$ & & & \\
\hline 31 & Puławy-Włostowice & & & & $\mathrm{X} ?$ & $\mathrm{X}$ & $\mathbf{X}$ & $\mathrm{X}$ & & \\
\hline 15 & Gościeradów I & & & & & $\mathbf{X}$ & $\mathbf{X}$ & $\mathbf{X}$ & & \\
\hline 17 & Jakubowice & & & & & $\mathrm{X}$ & $\mathbf{X}$ & $\mathrm{X}$ & & \\
\hline 19 & Kraśnik Piaski & & & & & $\mathbf{X}$ & $\mathbf{X}$ & $\mathbf{X}$ & & \\
\hline 22 & Lublin-Sławin 3 & & & & & & $\mathrm{X} ?$ & $\mathrm{X} ?$ & & \\
\hline 24 & Lublin-Zemborzyce & & & & & & & $\mathbf{X}$ & & \\
\hline 14 & Dratów II & & & & & $\mathbf{X}$ & $\mathrm{X}$ & $\mathbf{X}$ & $\mathrm{X} ?$ & \\
\hline 26 & Nieszawa Kolonia & & & & & $\mathbf{X}$ & $\mathbf{X}$ & $\mathbf{X}$ & $\mathbf{X}$ & \\
\hline 27 & Opoka & & & & & $\mathrm{X}$ & $\mathbf{X}$ & $\mathbf{X}$ & $\mathbf{X}$ & \\
\hline
\end{tabular}

cont. Tab. 1 


\begin{tabular}{|c|c|c|c|c|c|c|c|c|c|c|}
\hline Nr. & Ort & $\mathrm{A} 2$ & A3 & B1a & B1b & B2a & $\mathrm{B} 2 \mathrm{~b}$ & $\mathrm{~B} 2 / \mathrm{C} 1$ & C1a & $\mathrm{C} 1 \mathrm{~b}$ \\
\hline \multicolumn{11}{|c|}{ cont. Subregion II. Westliches Lublinerland } \\
\hline 14 & Dobre 2 & & & & & & $\mathbf{X}$ & $\mathbf{X}$ & $\mathbf{X}$ & \\
\hline 25 & Łączki-Pawłówek & & & & & & & $\mathbf{X}$ & $\mathbf{X}$ & \\
\hline 30 & Podbórz 1 & & & & & & & $\mathrm{X}$ & $\mathbf{X}$ & \\
\hline \multicolumn{11}{|c|}{ Subregion III. Östliches Lublinerland } \\
\hline 40 & Lipsko & $\mathbf{X}$ & & & & & & & & \\
\hline 57 & Zubowice & $\mathbf{X}$ & & & & & & & & \\
\hline 39 & Jaszczów & & & & $\mathrm{X}$ & $\mathbf{X}$ & $\mathbf{X}$ & & & \\
\hline 54 & Wieprzec & & & & & $\mathrm{X} ?$ & $\mathbf{X}$ & & & \\
\hline 59 & Żdżanne & & & & & $\mathrm{X} ?$ & $\mathrm{X}$ & & & \\
\hline 48 & Strzyżów 9 & & & & & & & $\mathrm{X}$ & & \\
\hline 58 & Zubowice 1 & & & & & & & $\mathrm{X}$ & & \\
\hline 42 & Perespa & & & & & & $\mathrm{X}$ ? & $\mathrm{X}$ & $\mathbf{X}$ & \\
\hline 53 & Werbkowice-Kotorów & & & & & & $\mathrm{X}$ ? & $\mathrm{X}$ & $\mathrm{X}$ & \\
\hline 34 & Dąbrowa & & & & & & & $\mathrm{X}$ & $\mathrm{X}$ & \\
\hline 36 & Gródek nad Bugiem & & & & & & & $\mathrm{X}$ & $\mathbf{X}$ & \\
\hline 37 & Horodysko & & & & & & & $\mathrm{X}$ & $\mathrm{X}$ & \\
\hline 44 & Podlodów 2 & & & & & & & $\mathrm{X}$ & $\mathrm{X}$ & \\
\hline 45 & Przewodów & & & & & & & $\mathrm{X}$ & $\mathrm{X}$ & \\
\hline 47 & Stefankowice & & & & & & & $\mathrm{X}$ & $\mathrm{X}$ & \\
\hline 55 & Wołajowice & & & & & & & $\mathrm{X}$ & $\mathbf{X}$ & \\
\hline 51 & Topornica 21-22 & & & & & & & $\mathrm{X}$ & $\mathbf{X}$ & \\
\hline 52 & Tuczapy 36 & & & & & & & $\mathbf{X}$ & $\mathbf{X}$ & \\
\hline 58 & Zubowice Siedlung & & & & & & & $\mathrm{X}$ & $\mathbf{X}$ & \\
\hline 38 & Husynne Kolonia & & & & & & & & $\mathbf{X}$ & \\
\hline 35 & Góra Grabowiec & & & & & & & & $\mathbf{X}$ & \\
\hline 41 & Obrowiec & & & & & & & & $\mathrm{X}$ & \\
\hline 43 & Podlodów 1 & & & & & & & & $\mathrm{X}$ & \\
\hline 49 & Swaryczów & & & & & & & & $\mathrm{X}$ & \\
\hline 46 & Romanów Hortfund & & & & & & & & $\mathrm{X}$ & \\
\hline 50 & Swaryczów Hortfund & & & & & & & & $\mathrm{X}$ & \\
\hline 56 & Wronowice-Paprzyca 5 & & & & & & & & $\mathrm{X}$ & \\
\hline
\end{tabular}

cont. Tab. 1. Die Przeworsk-Kultur im Lublinerland (A2-C1) 


\section{SUBREGION I}

Hier verfügen wir über differenzierte Kenntnis von fünf Gräberfeldern, drei Siedlungen und einem Einzelfund. So tauchten hier die Przeworsk-Siedler in der jüngeren vorrömischen Eisenzeit auf (die gut datierten Fundkomplexe deuten auf die Stufe A2 hin - Abb. 1); somit entstand nördlich des unteren Wieprz eine Besiedlungskonzentration in Form einer dicht besiedelten Insel, „WieprzProvinz" genannt, die deutlich vom masowischen Przeworsk-Besiedlungsgebiet abgetrennt ist (T. Dąbrowska 2008, Karte 2). Diese „Insel“ war damals die südlichste Besiedlungskonzentration der Przeworsk-Kultur östlich der Weichsel (A. Kokowski 1999a). Das lange Abhalten vom Überschreiten des WieprzTals nach Süden wurde wahrscheinlich durch Respekt vor den Bastarnen im Ostteil des Lublinerlandes verursacht, die archäologisch als Czerniczyn-Gruppe der Jastorf-Kultur bestätigt sind. Die Bastarnen sind hierher früher, an der Wende des 4. und 3. Jh. v. Chr. eingewandert. Ein Teil davon siedelte sich für fast 300 Jahre in der Hrubieszów-Becken und breiten Umgebung (A. Kokowski 2001a, 23-27; Ders. 2009, 182-183). Obwohl keine Nekropolen und Siedlungen der Bastarnen zwischen Weichsel und Wieprz bisher registriert worden sind, war eine große Überraschung die Entdeckung eines Kultplatzes im Südteil des Lublinerlandes, in Pikule, Kr. Janów Lubelski (A. Kokowski, P. Łuczkiewicz 2002; M. Florek, J. Libera 2006, 103, 110-111, 113 Taf. VI, VII'1). Auf dem SandHügel zwischen Mooren wurden dort Waffen und landwirtschaftliche Geräte während verschiedenen Votivhandlungen deponiert.

In Subregion I dauerte die Besiedlung der Przeworsk-Kultur ununterbrochen weiterhin während der römischen Kaiserzeit (Abb. 2-4). Nach wie vor funktionierte die „Wieprz-Provinz“, wie es die früher gegründeten Siedlungen in Drążgów, Fpl. 2-3 und Sobieszyn, Fpl. 14 belegen. In der letztgenannten ist Eisenschmelzung belegt (P. Łuczkiewicz 2008a), die älteste Spur davon östlich der Weichsel. Die Nekropolen von Masów, Drążgów, Fpl. 1 (A. Kokowski 1991, 25-45; A. Kokowski, A. Reszczyńska, E. Roman 1997) und Sobieszyn, Fpl. 1 (A. Kokowski 1991, 64-68; P. Łuczkiewicz 2015) wurden weiterhin belegt.

Die Besiedlung der Przeworsk-Kultur hört in etwa gleicher Zeit auf, in der Stufe B2/C1 (Abb. 5). Interessant in diesem Kontext ist die Entdeckung und vollständige Ausgrabung eines przeworskisches Hofes in Tarkawica, ausschließlich in die Stufe B2/C1 datiert. Aufgrund der Tongefässe ist es zu vermuten, dass die Einwohner aus Nordmasowien in diese Gegend kamen (Juściński 2008). Allein die Siedlung in Sobieszyn, Fpl. 14 scheint noch in der Stufe $\mathrm{C} 1 \mathrm{a}$ zu funktionieren, was zwei frühe Eisenfibeln A.158 belegen (P. Łuczkiewicz

1 Die Autoren erwähnen auch ein Hohleisen aus Łążek Ordynacki (M. Florek, J. Libera 2006, 103, Taf. VI:a), das seine genauen Entsprechungen in etwa dutzend Exemplaren von Pikule findet. 
2008, 272-273 Abb. 18:1). Da die beiden in der Kulturschicht gefunden wurden, ist ihr Zusammenhang mit der älterkaiserzeitlichen Siedlung unsicher. In die Stufe C1a datiert wahrscheinlich das Schwert aus Zawieprzyce vom Typ etwa Gruppe VIII nach Biborski, jedoch ohne genaue Entsprechung. Es ist zwar auf einer Seite mit einer breiten Blutrinne, auf der anderen mit zwei schmalen versehen, wie Typ Biborski/llkjær 8e (M. Biborski, J. Ilkjær 2006, 158 Abb. 106). Der Stich fehlt, was die richtige Zuweisung erschwert (A. Kokowski 1995, 29, 34 Abb. 4). Am wahrscheinlichsten scheint die Datierung in die Gebrauchszeit von Schwertern Gruppe VIII nach Biborski, d. h. in die Stufe B2/C1-C1a.

\section{SUBREGION II}

Aus diesem Gebiet sind sieben Nekropolen, zwei Einzelgräber, zehn Siedlungen und drei Einzelfunde bekannt. So ist es zu vermuten, dass die Region durch die Vertreter der Przeworsk-Kultur noch in der jüngeren vorrömischen Eisenzeit besucht war (Abb. 1), worauf ein einzelnes Tongefäß von Ort Iłki auf der NałęczówHochebene hindeutet (A. Uzarowiczowa 1970). Die richtige Besiedlung beginnt erst im entwickelten Stadium der älteren Kaiserzeit (B2a - Abb. 4). Für noch frühere Kolonisation spricht der älteste Fundkomplex 3/1988 der PrzeworskKultur von Puławy-Włostowice, Fpl. 3, mit einem Schildbuckel etwa vom Typ 5/6 nach Jahn, vermutlich vom Ausgang der Stufe B1 (B. Niezabitowska-Wiśniewska 2018, 502).

Im neubesetzten Gebiet sind nur spärliche Besiedlungspuren, besonders in dessen Westteil, registriert worden (M. Juściński 2008, 340-341; M. StasiakCyran 2016b, 162 Abb. 1). Erwähnenswert sind zwei Siedlungen der PrzeworskKultur. Eine davon, im großen Teil ausgegraben liegt in Ort Podbórz, Fpl. 1 bei Kurów, wo alles spricht dafür, dass hier Gerberhandwerk betrieben wurde, da am Siedlungsrand große Becken zum Lederaufweichen entdeckt worden sind ${ }^{2}$. Es wurden hier andere interessante Objekte gefunden, wie ein Kalkbrenn- und ein Backofen (M. Stasiak-Cyran 2016b, 166-170). In der zweiten, jahrelang untersuchten Siedlung in Nieszawa Kolonia fand man Spuren der Fischerei (M. Stasiak-Cyran 2016a). Es wurden hier hauptsächlich Reste vom Stör, aber auch von Barsch, Brasse, Hecht und karpfenartigen Fischen identifiziert (A. Witkowski 2016; M. Stasiak-Cyran 2018b). Darüber hinaus, sind mindestens drei größere, gut untersuchte Nekropolen bekannt, in Opoka (E. Szarek-Waszkowska 1971; A. Kokowski 1991, 96-116; Ders. 1994a; M. Stasiak 1994), Puławy-Włostowice (B. Niezabitowska-Wiśniewska 2018) und Kraśnik-Piaski (Z. Wichrowski 1997;

${ }^{2}$ Ähnliche Objekte wurden von Viktor Vojnarovs'kyj (2013) im Bereich der Černjachov-Kultur identifiziert. 


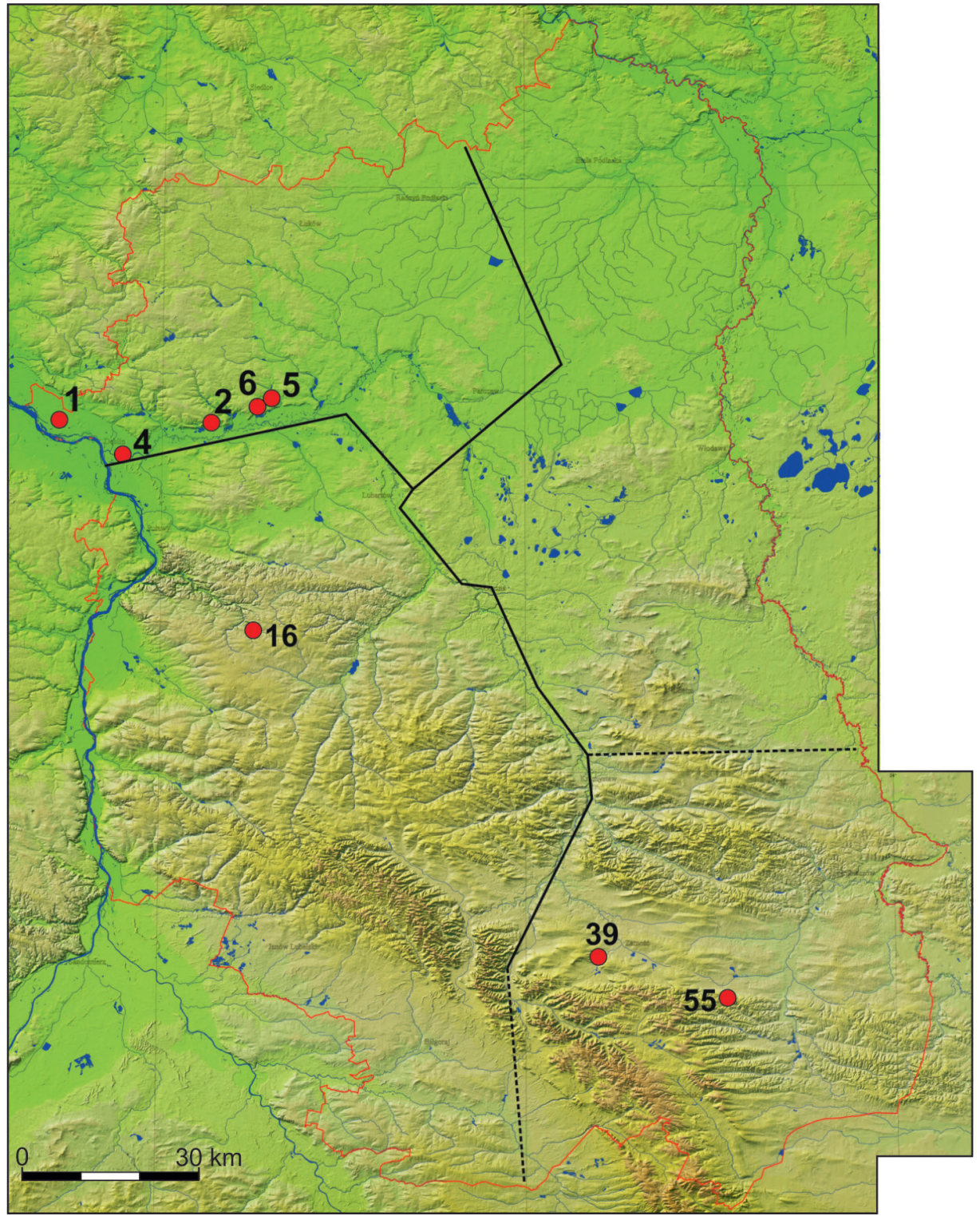

Abb. 1. Gut datierte Fundstellen aus der Stufe A2 der jüngeren vorrömischen Eisenzeit im Lublinerland. Die Nummern entsprechen der Liste I und der Tab. 1 (aufgrund der Karte „Lubliner Woiwodschaft“, L. Gawrysiak 2004)

Fig. 1. Well dated sites from the phase A2 of the younger pre-Roman period in Lublin Land. Numbers correspond with compilation I and with those presented in Tab. 1.

(based on the map "Województwo Lubelskie" by L. Gawrysiak 2004) 


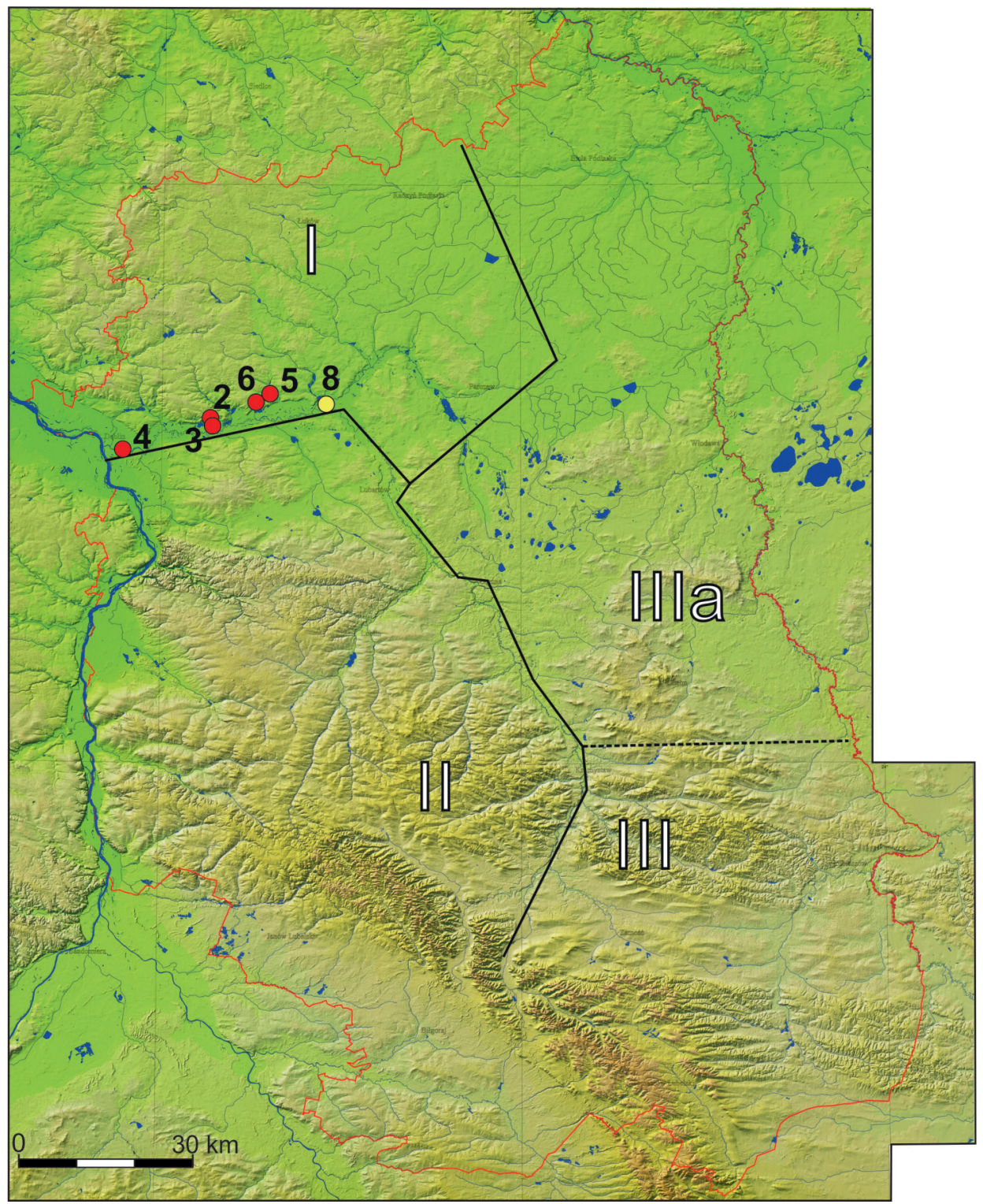

Abb. 2. Gut datierte Fundstellen aus der Stufe A3 der jüngeren vorrömischen Eisenzeit und der Stufe B1a der römischen Kaiserzeit im Lublinerland. Die Nummern entsprechen der Liste I und der Tab. 1 (aufgrund der Karte „Lubliner Woiwodschaft“, L. Gawrysiak 2004)

Fig. 2. Well dated sites from the phase A3 of the younger pre-Roman period and phase B1 of Roman period in Lublin Land. Numbers correspond with compilation I and with those presented in Tab. 1. (based on the map "Województwo Lubelskie" by L. Gawrysiak 2004) 


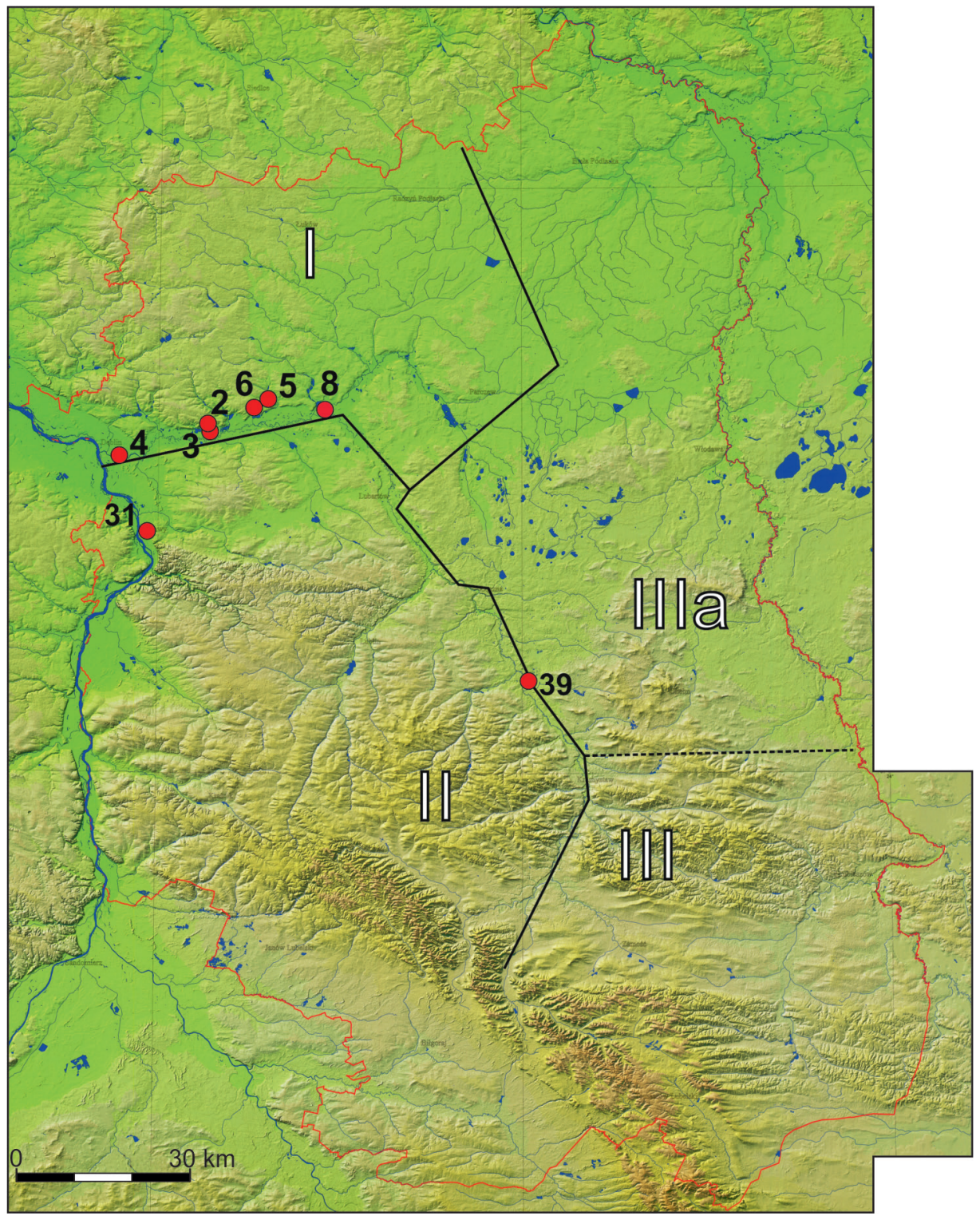

Abb. 3. Gut datierte Fundstellen aus der Stufe B1b der römischen Kaiserzeit im Lublinerland. Die Nummern entsprechen der Liste I und der Tab. 1 (aufgrund der Karte „Lubliner Woiwodschaft“, L. Gawrysiak 2004)

Fig. 3. Well dated sites from the phase B1b of the Roman period in Lublin Land. Numbers correspond with compilation I and with those presented in Tab. 1. (based on the map "Województwo Lubelskie" by L. Gawrysiak 2004) 


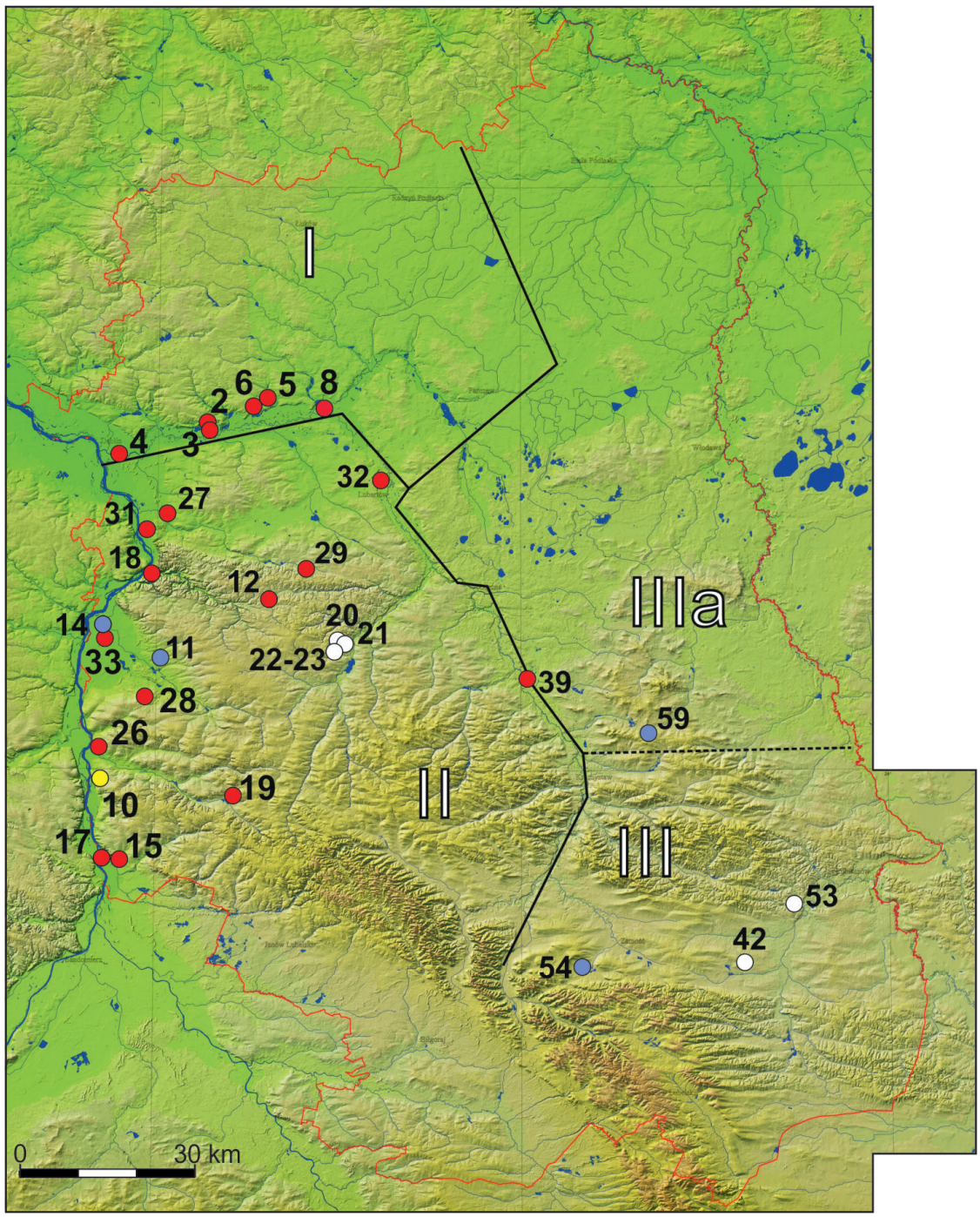

Abb. 4. Gut datierte Fundstellen aus der Stufe B2 der römischen Kaiserzeit im Lublinerland. Gelb - B2a; rot - B2; blau - B2b; weiss - Datierung im Rahmen der älteren Kaiserzeit unsicher. Die Nummern entsprechen der Liste I und der Tab. 1 (aufgrund der Karte „Lubliner Woiwodschaft“, L. Gawrysiak 2004)

Fig. 4. Well dated sites from the phase B2 of the Roman period in Lublin Land. Yellow sites dated solely to the phase B2a; red - site from the phase B2; blue - site from the phase B2b; white - uncertain chronology in frames of this time period. Numbers correspond with compilation I and with those presented in Tab. 1.

(based on the map "Województwo Lubelskie" by L. Gawrysiak 2004) 


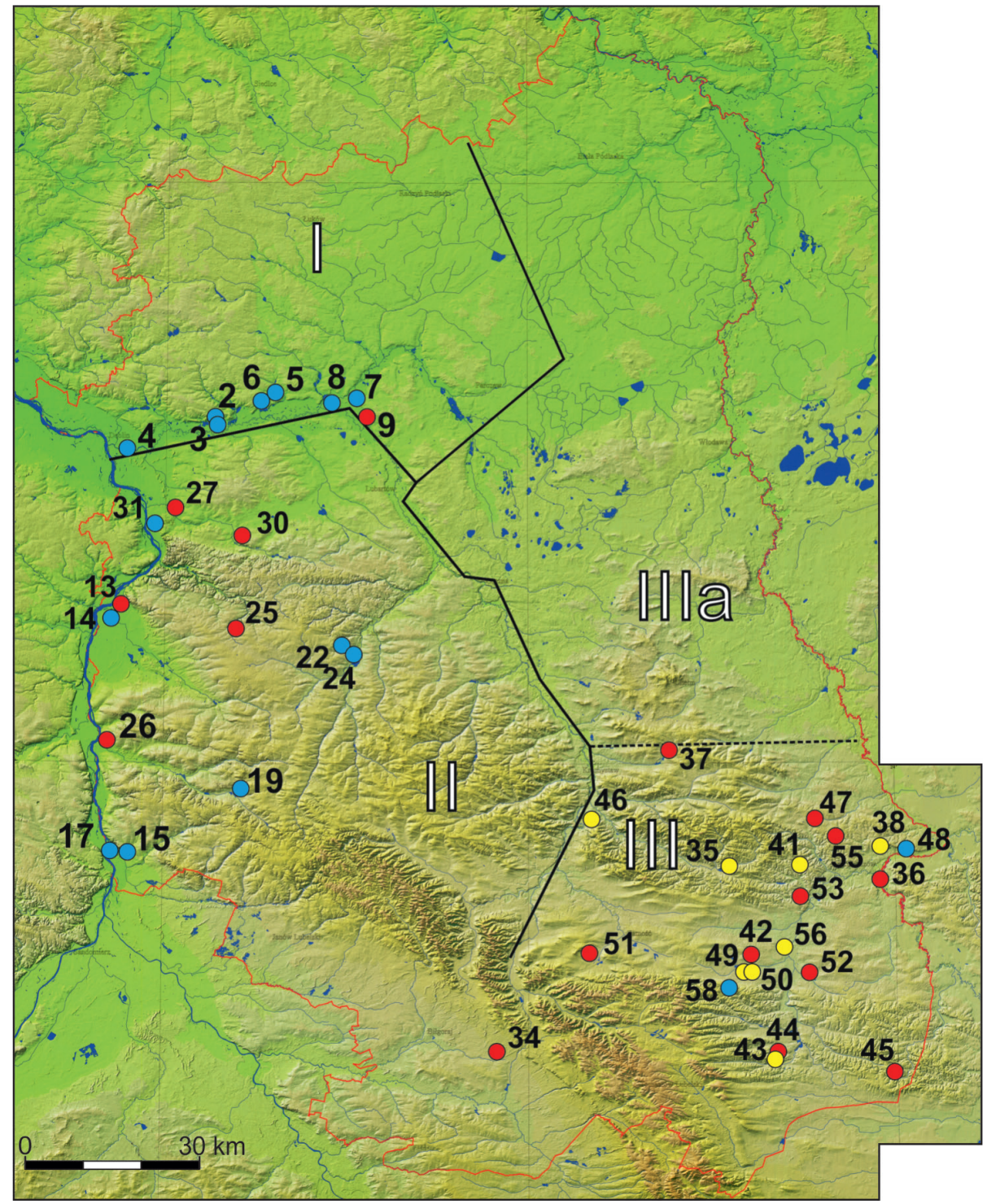

Abb. 5. Gut datierte Fundstellen aus der Stufe B2/C1-C1a der römischen Kaiserzeit im Lublinerland. Blau - B2/C1; rot - B2/C1-C1a; gelb - C1a. Die Nummern entsprechen der Liste I und der Tab. 1 (aufgrund der Karte „Lubliner Woiwodschaft“, L. Gawrysiak 2004)

Fig. 5. Well dated sites from the phase B2/C1 - C1a of the Roman period in Lublin Land. Blue - site from the phase B2/C1; red - site from the phase B2/C1 - C1a; yellow - site from the phase C1a. Numbers correspond with compilation I and with those presented in Tab. 1. (based on the map "Województwo Lubelskie" by L. Gawrysiak 2004) 
Ders. 1998; Der. 1999; Ders. 2000; Ders. 2003; Ders. 2004). Nach Süden reicht die Besiedlung bis Gościeradów, woher wieder ein Brandgräberfeld bekannt ist (A. Niewęgłowski 1982); die kleineren Siedlergruppen zerstreuten sich in der Gegend von Jakubowice, Opole Lubelskie, Dratów (Fpl. 1), Dobre (Fpl. 2), Kazimierz Dolny, Szczekarków (A. Kokowski 1991, 184 Abb. 88) und Bliskowice (M. StasiakCyran 2018a). Außer Siedlungspuren sind es meistens auch Grabfunde.

Die Bevölkerung der Przeworsk-Kultur hat ebenfalls den östlichen Teil der Subregion II besetzt. Die bestuntersuchte Siedlung in Lublin-ZemborzyceDąbrowa (A. Kloss 1991; A. - R. Niedźwiadkowie 1997; Ders. 1998) entstand nicht früher, als erst am Ende des 2. Jh. n. Chr. (Stufe B2/C1), zumindest eine Generation später als andere Fundstellen der Region. Weitere Reste einer Siedlung, scheinbar aus der entwickelten Phase der älteren Kaiserzeit, mit wichtigen Relikten der Gabelpfosten-Pfetten-Dachkonstruktion wurden in Lublin-Sławin-Szerokie, Fpl. 3 entdeckt (M. Stasiak-Cyran 2016b, 165-166). In der Stadt Lublin, an der Kreuzung der Duch- und Solidarność-Strasse kam ein Kalkbrenn- bzw. Töpferofen (?) der Przeworsk-Kultur (?) zum Vorschein (J. Tkaczyk 2017, 159). Weitere Angaben zu den älterkaiserzeitlichen Funden aus anderen Teilen der Stadt, in Hajdów-Zadębie (R. Niedźwiadek 2017, 266 Abb. 1) und Wola Sławińska (S. Żórawski 2017, 385 Abb. 1) sind sehr unpräzis. Westlich von Lublin ist noch eine Siedlung in Cynków bei Nałęczów zu notieren, in der im Jahre 1964 eine Grube mit zerbrochenen Tongefässen untersucht wurde (A. Kokowski 1991, 92-95).

Ein Beweis dafür, wie wenig wir über das Besiedlungsbild der Subregion II in den ersten zwei Jahrhunderten n. Chr. wissen, sind römische Münzfunde, im ganzen Gebiet verstreut (A. Kokowski 1991, 151 Abb. 76). Dieser Teil des Lublinerlandes erweist sich kulturell als am meisten homogen, da die WielbarkKultur hierher sehr spät und im nicht besonders starken Ausmaß kommt ${ }^{3}$. Somit dürfen die Münzfunde aus der Zeit bis zum Ende des 2. Jh. mit großem Vorbehalten mit der Przeworsk-Besiedlung verbunden werden.

\section{SUBREGION III}

Es sind uns sechs Nekropolen, zehn Einzelgräber, fünf Einzelfunde, zwei Horte, eine sichere Siedlung in Zubowice und eine angebliche in Topornica bekannt. Das Besiedlungsbild ist hier am meisten kompliziert, nicht nur in Hinblick auf die erwähnten Funde der Czerniczyn-Gruppe der Jastorf-Kultur, aber auch auf

3 Bis auf eine Ausnahme des Fundmaterials von Puławy-Włostowice, wo die Funde der WielbarkKultur vermutlich bereits in die Stufe C1 datiert sind (B. Niezabitowska-Wiśniewska 2018, 601-630). 
deutliche Spuren der Zarubinjetz-Kultur entlang des Bug (A. Kokowski 1991, 180f.; A. Kokowski 2009, 183-185). In der jüngeren vorrömischen Eisenzeit war der ganze Nordteil der Subregion III durch Gruppen der Jastorf-Kultur besetzt (T. Dąbrowska 2008, 93-100, Karte 6).

Zwar treten die ältesten Spuren der Przeworsk-Kultur bereits während der jüngeren vorrömischen Eisenzeit auf, es sind aber nur Einzelgräber wie in Zubowice (Kokowski 1991, 46-51) zu nennen, wo eine Bestattung mit der Fibel Kostrzewski K in die Stufe A2 datiert wird oder eine kleine, etwa zeitgleiche Nekropole in Lipsko (Abb. 1) bei Zamość (Drewko 1957). Ihr Auftreten ist vermutlich mit der inselartigen Besiedlung nördlich von Lemberg zu verbinden (Kozak 1984, 36-37, 44 Tabelle 4).

Ein Phänomen ist das Gräberfeld in Jaszczów am rechten Ufer des Wieprz mit den Funden möglicherweise aus der Stufe B1 (Kokowski 1991, 116-127). Bisher ist es der einzige Beleg der Penetration der Przeworsk-Kultur östlich des Wieprz nach Osten und Südosten (Abb. 3).

Alles spricht dafür, dass die zweite Welle der Przeworsk-Siedler die Subregion erst am Ende der älteren und in der mittleren Kaiserzeit erreichte (Abb. 4-5). Es handelt sich hier vorwiegend um Waffengräber; bisher ist nur eine Frauenbestattung von Tuczapy, Fpl. 36 u. a. mit metallenen Kästchenbeschlägen bekannt. Weiterhin ist eine Siedlung von Zubowice, Fpl. 1 zu nennen (Sadowski 2006). In der Sammlung von Streufunden von Perespa mit u. a. einem eisernen Schildbuckel (Łuczkiewicz 2006) befinden sich zwar Glasperlen, deren Zugehörigkeit zu der Przeworsk-Kultur wenig wahrscheinlich scheint. Die jüngsten Funde reichen nicht über die Stufe C1a (Abb. 5), wenn die Spuren der Przeworsk-Kultur aufhören. Wesentlich ist, dass fast alle Funde vom militärischen Charakter sind und dass außer Zubowice andere Siedlungen der Przeworsk-Kultur fehlen.

Zwischen der gut dokumentierten Welle der Przeworsk-Siedler aus der jüngeren vorömischen Eisenzeit und der nächsten, aus der mittleren Kaiserzeit, treten in Subregion III am Ausgang der jüngeren vorrömischen Eisenzeit und in der frühen Kaiserzeit zuerst die Fundstellen der Zarubinjetz-Kultur (A. Kokowski 1991, 180f.; A. Kokowski 2009, 183-185) und danach die älterkaiserzeitlichen Funde auf, wie eine Augenfibel der preußischen Nebenserie Almgren III (B. Niezabitowska 2004) und verwandte, letztlich als Typ Husynne bezeichnet. Ihr Kulturkontext ist immer noch nicht ganz klar, vielmehr aber nicht vom Przeworsk-Charakter, da die Grabfunde fehlen. Vieles spricht dafür, dass die genannten Funde die Kultursituation östlich des Bug dokumentieren, die sich als „Horizont der Spätzarubinjetz-Funde” bestimmen lässt (B. NiezabitowskaWiśniewska 2017). Es sieht so aus, als diese Besiedlung stark genug war, um ein erfolgreiches Hindernis für die Przeworsk-Bevölkerung zu werden. 


\section{SCHLUSSBEMERKUNGEN}

„Erstes Ende“ der Besiedlung der Przeworsk-Kultur in allen Subregionen des Lublinerlandes ist das Resultat der Expansion der Wielbark-Kultur (A. Kokowski 1999b). Die mit ihr identifizierten Goten haben zuerst die Hrubieszów-Becken untergeordnet, in der ein wichtiges Kultur-, Wirtschafts- und Handelszentrum entstand, die so genannte Masłomęcz-Gruppe (vgl. A. Kokowski 1999c; Ders. 1999d; Ders. 2007, 99-158; Ders. 2009, 187-198). Im ganzen Streifen der Lubliner(Subregion III) und der Wolhynien-Hochebene kam es zur Konfrontation mit den Wandalen, was verstreute Waffengräber (gegen nur einen Frauengrab von Tuczapy Fpl. 36) und kleine Nekropolen der Przeworsk-Kultur belegen (das Problem der militärisches Konflikt in diese Gegend ist in folgende Literatur diskutiert - A. Kokowski 2005; Ders. 2008; Ders. 2009, 185-187). Es scheint jedoch, dass die Angreifer die Besetzung der Subregion II zwischen Weichsel und Wieprz, in seinen Plänen noch nicht hatten, da sie erst - wie es belegt wurde - in dieser Region in der späten Phase der jüngeren Kaiserzeit auftauchten.

Es ist möglich, das absolute Datum des ersten Endes der Przeworsk-Kultur festzulegen. In Swaryczów wurde ein römischer Münzschatz im PrzeworskTongefäß entdeckt (M. Heisig 1950; T. Dąbrowska 1962). Der Topf lässt sich in die mittlere Kaiserzeit datieren und die Schlussmünze ist ein Denar des Pertinax im Jahre 193 n. Chr. geprägt. Der zweite Münzschatz im Przeworsk-Tongefäß stammt aus Romanów (A. Kunisz 1972, 96 Abb. 2) und darf ebenfalls in die mittlere Kaiserzeit datiert werden (A. Kokowski 1985a, 40f.). Die Schlussmünze ist hier ein Denar des Septimius Severus aus dem Jahre $194 \mathrm{n}$. Chr. Somit ist terminus ante quem für das Eingraben der beiden Horte in die Jahre 193-194 n. Chr. einzusetzen. Die gut dokumentierten Münzdeposite aus dem Lublinerland sitzen im Horizont bis zum Beginn des 3. Jh. (Liste II) und lassen sich ohne jeden Zweifel mit der Migration der Wielbark-Kultur nach Süden zu verbinden (A. Kokowski 1985a, 36 Abb. 3; 37 Abb. 5; 39 Abb. 6). Interessanterweise wurden die meisten registrierten Deposite im Südteil der Subregion III gefunden (Abb. 6), wo sich die oben erwähnten Konfliktspuren beobachten lassen. Somit scheint es berechtigt, die Kämpfe in den Jahren 193-218 n. Chr. oder kurz danach zu platzieren, da auf das letzte Datum die Schlussmünze aus dem Hort in Spiczyn hinweist.

Fig. 6. Hoards of coins emitted before II/III century AD (after M. Gładysz-Juścińska, M. Juściński 2010, 38 Fig. 1, changed); red - coins in the pots of the Przeworsk culture; yellow - hoards known partially; white - information about the hoard of Roman coins. Numbers correspond to the compilation II

(based on the map "Województwo Lubelskie" by L. Gawrysiak 2004) 


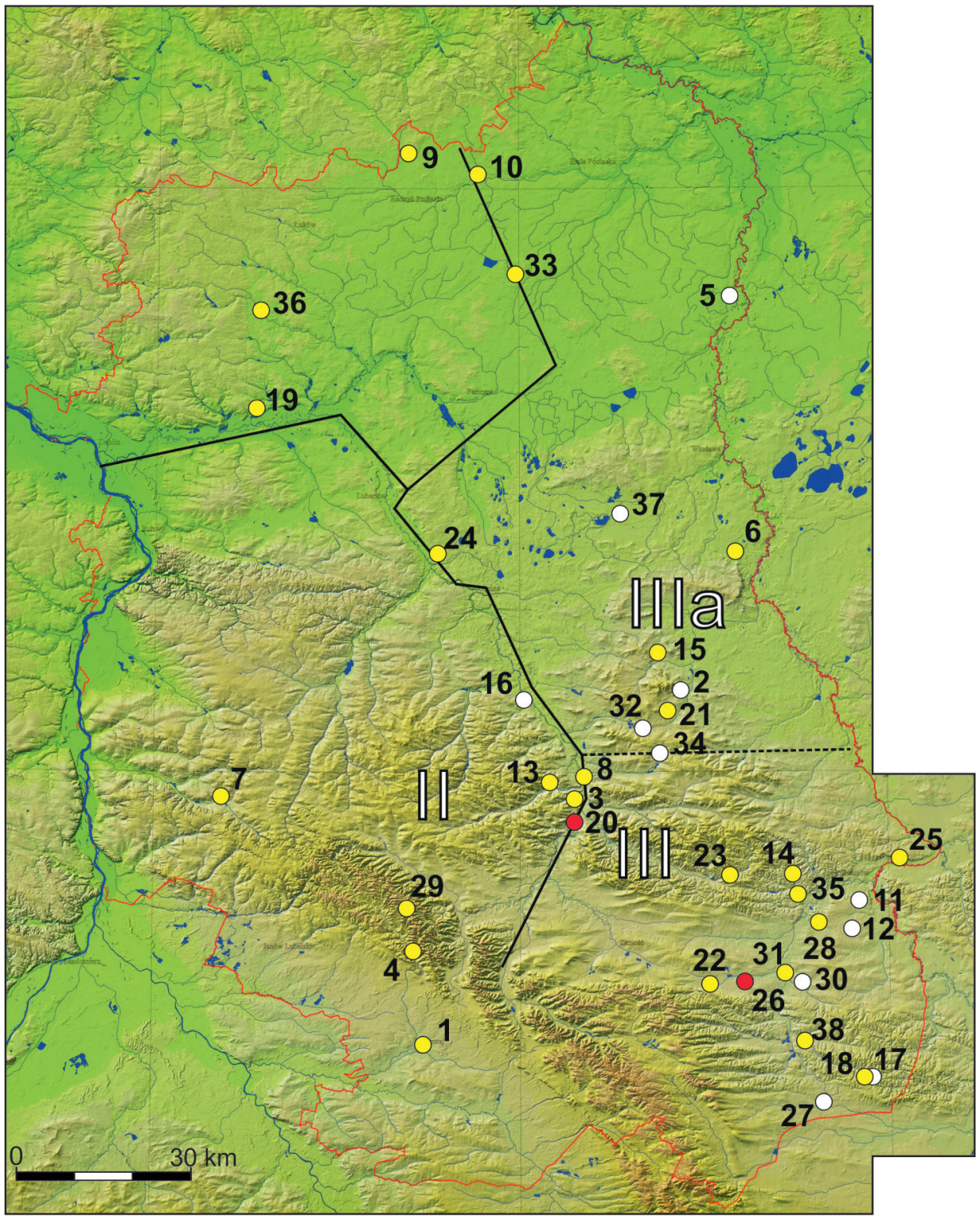

Abb 6. Münzschätze mit Prägungen bis zum 2./3. Jh. n. Chr. (nach. M. Gładysz-Juścińska, M. Juściński 2010, 38 Abb. 1 mit Ergänzungen). Rot - Münzen in Tongefässen der PrzeworskKultur; gelb - Schätze mit teilweise bekanntem Inhalt; weiss - Information von einem Schatz. Die Nummern entsprechen der Liste II (aufgrund der Karte „Lubliner Woiwodschaft“, L. Gawrysiak 2004). 
LISTE I.

FUNDSTELLEN UND GUT DATIERTE FUNDE DER PRZEWORSK-KULTUR AUS LUBLINERLAND ${ }^{4}$

\section{Subregion I. Nordwestliches Lublinerland}

1. Brzeźce, Gem. Stężyca, Kr. Ryki. Grab (Gräberfeld?). A2 (Gajewski 1999).

2. Drążgów, Gem. Ułęż, Kr. Ryki, Fpl. 1. Gräberfeld, A2-B2/C1 (Castagne, Kokowski 1989; Kokowski, Machul, Rogatko 1988; Kokowski 1990; Ders. 1991, 25-45; Ders. 1997, 112 Abb. 12; Kokowski, Reszczyńska, Roman 1997).

3. Drąż̇ów, Gem. Ułęż, Kr. Ryki, Fpl. 2-3. Siedlung, A3-B2/C1 (Castagne, Kokowski 1989; Kokowski 1989; Gładysz, Kokowski 1997).

4. Masów (Dęblin), Gem. loco, Kr. Ryki. Gräberfeld, A2-B2/C1 (Gurba 1954; Ders. 1958; Kokowski 2001b; Stasiak-Cyran 2003b; Dies. 2004a).

5. Sobieszyn, Gem. Ułęż, Kr. Ryki, Fpl. 14. Siedlung, A2-B2/C1 (C1a?) (Łuczkiewicz 2008a; Ders. 2008b).

6. Sobieszyn, Gem. Ułęż, Kr. Ryki, Fpl. 1. Gräberfeld, A2-B2/C1 (Kokowski 1991, 64-68; Łuczkiewicz 2015).

7. Tarkawica, Gem. Ostrówek, Kr. Lubartów, Fpl. 5. Hof, B2/C1 (Juściński: 2003; Ders. 2003a; Ders. 2003b; Ders. 2004a; Ders. 2004b; Ders. 2008);

8. Wola Skromowska, Gem. Firlej, Kr. Lubartów. Gräberfeld, B1-B2/C1 (Kokowski, Kutyłowski 1987; Kokowski 2004);

9. Zawieprzyce, Gem. Spiczyn, Kr. Łęczna. Einzelfund (Schwert), B2/C1-C1a (Kokowski 1995, 29, 34 Abb. 4).

\section{Subregion II. Westliches Lublinerland}

10. Bliskowice, Gem. Annopol, Kr. Kraśnik. Grab (Gräberfeld?), B2a (StasiakCyran 2018a).

11. Chodel, Gem. Wilków, Kr. Opole Lubelskie, Fpl. 28. Siedlung, B2 (StasiakCyran 2016b, 168).

12. Cynków, Gem. Nałęczów, Kr. Puławy. Siedlung, B2 (Kokowski 1991, 92-95).

13. Dobre, Gem. Wilków, Kr. Opole Lubelskie, Fpl. 2. Siedlung, B2/C1-C1a (Czopek 1980; Kokowski 1991, 69-82).

14. Dratów (Zagłoba), Gem. Wilków, Kr. Opole Lubelskie, Fpl. II (Góra Sowalińska). Gräberfeld, B2-B2/C1? (Chotyński 1908; Ders. 1911, 51-60).

15. Gościeradów, Gem. loco, Kr. Kraśnik, Fpl. 1. Gräberfeld, B2-B2/C1 (Niewęgłowski 1982).

${ }^{4}$ Die Literaturhinweise werden auf die vollständigsten oder aber solche, die wesentlich die älteren Publikationen modifizieren, beschränkt. 
16. Iłki (Wąwolnica), Gem. Wąwolnica, Kr. Puławy. Einzelfund (Tongefäß), A2 (Uzarowiczowa 1970).

17. Jakubowice, Gem. Annopol, Kr. Kraśnik. Gräberfeld, B2-B2/C1 (Dąbrowska 1963a).

18. Kazimierz Dolny, Gem. loco, Kr. Puławy. Grab (?), Einzelfunde (Feuerstahl Typ IAb), B2 (Kokowski 1985c, 118 Abb. 2).

19. Kraśnik-Piaski, Gem. Kraśnik, Kr. Kraśnik. Gräberfeld, B2-B2/C1 (Wichrowski 1997; Ders. 1998; Ders. 1999; Ders. 2000; Ders. 2003; Ders. 2004).

20. Lublin, Ducha / Solidarności-Strasse. Siedlung, B? (Tkaczyk 2017, 159).

21. Lublin-Hajdów-Zadębie. Siedlung, B? (Niedźwiadek 2017, 266 Abb. 1).

22. Lublin-Sławin-Szerokie. Siedlung, B2b-B2/C1? (Stasiak-Cyran 2016b, 165f.).

23. Lublin-Wola Sławińska. Siedlung, B? (Źórawski 2017, 385 Abb. 1).

24. Lublin-Zemborzyce-Dąbrowa, Fpl. 19. Siedlung, B2/C1 (Kloss 1991; Niedźwiadkowie 1997; Dies. 1998).

25. Lączki-Pawłówek, Gem. Borzechów, Kr. Lublin. Einzelfund (Lanzenspitze), B2/C1-C1a (Reszczyńska 2005).

26. Nieszawa Kolonia, Gem. Józefów nad Wisła, Kr. Opole Lubelskie. Siedlung, B2-C1a (Stasiak-Cyran 2016a).

27. Opoka, Gem. Końskowola, Kr. Puławy. Gräberfeld, B2a-B2/C1-C1a (SzarekWaszkowska 1971; Kokowski 1991, 96-116; Ders. 1994a; Stasiak 1994; StasiakCyran 2003c; Dies. 2004b).

28. Opole Lubelskie, Gem. und Kr. loco. Gräberfeld (zerstört), B2 (Dąbrowska 1963b).

29. Osówka, Gem. Niemce, Kr. Lublin. Einzelgrab, B2 (Nosek 1948).

30. Podbórz (Szumów), Gem. Kurów, Kr. Puławy, Fpl. 1. Siedlung, B2b-C1a (Stasiak-Cyran 2016b, 166-170).

31. Puławy-Włostowice, Gem. Puławy, Kr. Puławy, Fpl. 3. Gräberfeld B1c-B2/ C1 (Niezabitowska-Wiśniewska 2018).

32. Szczekarków, Gem. Lubartów, Kr. Lubartów. Grab (?), B (Kokowski 1991, 68f.). 33. Wrzelów, Gem. Łaziska, Kr. Opole Lubelskie. Grab (Gräberfeld?), B? (Chotyński 1911, 47)

Subregion III. Östliches Lublinerland ${ }^{5}$

34. Dąbrowa, Gem. Józefów, Kr. Biłgoraj. Einzelfund (Lanzenspitze), B2/C1C1a (Stasiak-Cyran 1999, 163f., 168 Abb. 1c).

\footnotetext{
${ }^{5}$ In der Zusammenstellung der Siedlungen der Przeworsk-Kultur nach M. Juściński (2008, 340341) sind Chełm-Bieławin, Fpl. 1 (2) und Ciechanki Łańcuchowskie, Fpl. 1, Kr. Łęczna, genannt worden. Im Vergleich mit den anderen Fundstellen aus dieser Region, besonders mit der großen Siedlung aus der jüngeren vorrömischen Eisenzeit in Horodysko, Fpl. 13, sind sie vielmehr den Objekten im „Jastorf-Stil” zuzuweisen (Łuczkiewicz 2016, 170f.). Dasselbe betrifft die vorrömischen
} 
35. Góra Grabowiec, Gem. Grabowiec, Kr. Zamość. Grab, C1a (Banasiewicz 1997a).

36. Gródek nad Bugiem, Gem. Hrubieszów, Kr. Hrubieszów. Einzelfunde (u.a. 2 Fibeln A.43, Waffenelemente). Grab (?), B2/C1-C1a (unpubliziert und Juściński $2009)^{6}$.

37. Horodysko, Gem. Leśniowice, Kr. Chełm, Fpl. 13. Gräberfeld, B2/C1 (Niezabitowska-Wiśniewska 2016).

38. Husynne Kolonia, Gem. Horodło, Kr. Hrubieszów, Fpl. 4. Einzelfunde (Sporn Ginalski F1, Messer, Eimeranhänger), C1a (Banasiewicz 1990, 38 Abb. 2:3-6).

39. Jaszczów, Gem. Milejów, Kr. Łęczna. Gräberfeld, B1-B2 (Kokowski 1991, 116-127).

40. Lipsko, Gem. Zamość, Kr. Zamość. Gräberfeld, A2 (Drewko 1957, 167; Kokowski 1991, 171).

41. Obrowiec, Gem. Hrubieszów, Kr. Hrubieszów. Grab, C1a (Kokowski 1991, 85-89).

42. Perespa, Gem. Tyszowce, Kr. Tomaszów Lubelski. Grab, B2?-C1a (Łuczkiewicz 2006).

43. Podlodów, Gem. Łaszczów, Kr. Tomaszów Lubelski, Fpl. 1. Grab, C1a (Gurba, Ślusarski 1964-1965; Stasiak-Cyran 2003a; Dies. 2004c).

44. Podlodów, Gem. Łaszczów, Kr. Tomaszów Lubelski, Fpl. 2. Gräberfeld, B2/ C1-C1a (Banasiewicz 1994; Bagińska, Banasiewicz, Niedźwiedź, Taras 2000, 77f.). 45. Przewodów, Gem. Dołhobyczów, Kr. Hrubieszów. Gräberfeld, B2/C1-C1a (Śmiszko 1932, 22-24; Kieferling 2002, 40-47; Kokowski 2009, 185 Abb. 6).

46. Romanów, Gem. Izbica, Kr. Krasnystaw. Münzschatz im Tongefäß der Przeworsk-Kultur, B2/C1-C1a (A. Kunisz 1972, 96 Abb. 2).

47. Stefankowice, Gem. Hrubieszów, Kr. Hrubieszów. „Fürstengrab”, B2/C1C1a (Kokowski 1985b, 166f. Taf. Ia).

48. Strzyżów, Gem. Horodło, Kr. Hrubieszów, Fpl. 9. Einzelfund (Fibel A.43), B2/C1 (Kokowski, Maleev 1999, 179 Abb. 1a).

49. Swaryczów, Gem. Komarów-Osada, Kr. Zamość. Grab, C1a (Kokowski, Kuśnierz, Urbański 1997; Dies. 2003; Dies. 2004).

50. Swaryczów, Gem. Komarów-Osada, Kr. Zamość. Münzschatz im Tongefäß der Przeworsk-Kultur, C1a (Heisig 1950; Dąbrowska 1962).

Funde aus der Siedlung in Garbatówka Kolonia, Fpl. 7, Kr. Łęczna (Polańska 2000, 23f). Als kaiserzeitlich wurde hier ein Objekt mit uncharakteristischem Material und einem Denar des Trajan bezeichnet (Polańska 2001, 35). Daher ist hier der Fundplatz nicht berücksichtigt worden.

${ }^{6}$ Zur umfangreichen Serie der Einzelfunde - Fibeln Almgrens Gruppen: IV, V und VII erheben sich wesentliche Zweifel: Vertreten sie die früheste Phase der gotischen Besiedlung (MasłomęczGruppe) oder aber die späteste der Przeworsk-Kultur? (Kokowski 2009, 188, Abb. 9). Dies betrifft auch andere Einzelfunde, besonders aus dem östlichen Lublinerland, die in die mittlere Kaiserzeit datiert werden, z. B. die Emailfibel von Wola Uhruska (Gładysz-Juścińska 2009). 
51. Topornica (Lipsko), Gem. Zamość, Kr. Zamość, Fpl. 21-22. Streufunde aus der Siedlung (?), u. a. Fibel A.43, A.V - masowische Serie, A.V - Typ Brzeźce, provinzialrömische Fibel etwa A.246; B2/C1-C1a (Kuśnierz 2005, 234 Taf. ID)7 . 52. Tuczapy, Gem. Mircze, Kr. Hrubieszów, Fpl. 36 (ursprünglich irrtümlich als Mołożów, Fpl. 5). Gräberfeld, B2/C1-C1a (unpubliziert, Sammlung S. Staszic Museum im Hrubieszów) $)^{8}$.

53. Werbkowice-Kotorów, Gem. loco, Kr. Hrubieszów. Grab (?), B2b-C1a (Stasiak-Cyran 1999).

54. Wieprzec, Gem. Zamość, Kr. Zamość. Einzelfund (Lanzenspitze), B (Kokowski 1991, 83f.).

55. Wolajowice, Gem. Hrubieszów, Kr. Hrubieszów. Einzelfunde (Grab?), B2/ C1-C1 (Kokowski 1995, 29, 35 Abb. 5).

56. Wronowice-Paprzyca, Gem. Werbkowice, Kr. Hrubieszów, Fpl. 5. Grab (?), C1a (Gajewski 1980).

57. Zubowice, Gem. Komarów-Osada, Kr. Zamość. Grab, A2 (Gajewski, Gurba, Kokowski 1981; Kokowski 1991, 46-51; Kokowski, Kuśnierz 2003; Bochnak, Opielowska-Nowak 2017).

58. Zubowice, Gem. Komarów-Osada, Kr. Zamość, Fpl. 1. Siedlung, B2/C1 (Sadowski 2006).

59. Żdżanne, Gem. Siennica Różana, Kr. Krasnystaw. Grab, B2? (Kokowski 1991, 83-86).

LISTE II.

MÜNZSCHÄTZE AUS LUBLINERLAND MIT PRÄGUNGEN

DES 2./2. JH. N. CHR. ${ }^{9}$

1. Biłgoraj, Gem. und Kr. loco, Nastawna-Strasse 68. Über 100 Münzen, davon 36 fassbar; Schlussmünzen: D Commodus (186-187), Rom, RIC 159, Commodus (180-192), Rom.

2. Chełm-Umgebung, Gem. und Kr. Chełm, Münzschatz (?), „mehrere Münzfunde", erkannt hochwahrscheinlich D Trajan (106-117).

\footnotetext{
${ }^{7}$ In der Sammlung befindet sich ein Fragment einer Augenfibel (A.III) und die Fibeln A.VII, sarmatische Serie sowie A.VII.192, die bereits der Wielbark-Kultur zugewiesen sein können.

${ }^{8}$ Für die Information darüber gilt Anna Hyrchała und Bartłomiej Bartecki, M.A., mein aufrichtiger Dank.

${ }_{9}^{9}$ Aufgrund des Manuskriptes „Corpus der römischen Funde im europäischen Barbaricum Lublinerland" (wo die volle Literatur). Weitere Literaturhinweise wurden nur zu den Funden angegeben, die in den Zusammenstellungen von A. Kokowski 1985a und A. Kokowski 1991 noch nicht berücksichtigt worden sind, und im Fall, wenn unsere Kenntnis der Fundumstände neulich wesentlich ergänzt wurde.
} 
3. Dworzyska, Gem. Tarnogóra, Kr. Krasnystaw 78 Münzen, D aus der Zeit des Antoninus Pius und Marc Aurel (138-180).

4. Goraj, Gem. loco. Kr. Biłgoraj. Münzschatz von etwa 200 Münzen, 7 davon bestimmt, Schlussmünze D Hadrian (117-138).

5. Kostomłoty, Gem. Kodeń, Kr. Biała, „am Bug”. Münzschatz (?), über 10 Münzen (Bienia 2003, 72).

6. Kosyń, Gem. Wola Uhruska, Kr. Włodawa. Münzschatz von über 200 Münzen, 2 davon fassbar, Schlussmünze D Marc Aurel (171-172), Rom, BMC IV 561-562, RIC 252.

7. Kraśnik, Gem. und Kr. loco. Münzschatz, davon 11 Münzen fassbar, Schlussmünze D Commodus (183-184), Rom, RIC, 94 B.

8. Krasnystaw, Gem. und Kr. loco. Münzschatz, davon 3 Münzen fassbar, Schlussmünze D Commodus (180-192).

9. Krzewica, Gem. Międzyrzec Podlaski, Kr. Biała Podlaska. Münzschatz von 472 Münzen, davon 7 fassbar, Schlussmünze Commodus (179-180), Rom, RIC 2.

10. Międzyrzec Podlaski, Gem. loco, Kr. Biała Podlaska. Münzschatz von über 500 Münzen, Schlussmünze Faustina d. Ältere (vor 175).

11. Mieniany, Gem. und Kr. Hrubieszów. Münzschatz von über 200 Münzen.

12. Modryniec, Gem. Mircze, Kr. Hrubieszów. Münzschatz von über 100 Münzen. Denare „u. a. aus der Trajans-Zeit”.

13. Namule, Gem. und Kr. Krasnystaw. Münzschatz (?), mehr als 3 Münzen, Schlussmünze D Antoninus Pius (151-154), RIC III 203219 bzw. 229a (Bursche 1999, 130f.).

14. Obrowiec, Gem. und Kr. Hrubieszów. Münzschatz von mehr als 68 Münzen, davon 12 fassbar, Schlussmünzen D Commodus (189), Rom, BMC IV 269 (?); D Septimius Severus (189-211).

15. Ochoża, Gem. Wierzbica, Kr. Chełm. Münzschatz von über 100 Münzen, davon 12 erhältlich, Schlussmünze Antoninus Pius (vor 161).

16. Oleśniki (manchmal irrtümlich als Oleśnica), Gem. Trawniki, Kr. Świdnik. Münzschatz (?) von über 200 Münzen.

17. Przewodów, Gem. Dołhobyczów, Kr. Hrubieszów. Münzschatz I. Über 100 Münzen, „griechisch und römisch”.

18. Przewodów, Gem. Dołhobyczów, Kr. Hrubieszów. Münzschatz II. Einige hundert Münzen, davon 150 fassbar, Schlussmünze D Commodus (186-187), Rom, RIC 157.

19. Przytoczno, Gem. Jeziorzany, Kr. Lubartów. Münzschatz, über 100 Münzen, davon D Domitian (81-96) fassbar.

20. Romanów, Gem. Izbica, Kr. Krasnystaw. Münzschatz von über 700 Münzen, davon 593 fassbar, Schlussmünze D Septimius Severus (194), Rom, BMC V 74-75 (Fedorowicz 1984; Ders. 2003, 5-91; Gładysz-Juścińska, Juściński 2010, 46 Fot. 2). 
21. Rożdżałów, Gem. und Kr. Chełm. Münzschatz, mehr als 47 Münzen, davon 47 fassbar, Schlussmünze D Julia Domna (211-217), Rom, RIC Car 385 b.

22. Ruszczyzna, Gem. Komarów Osada, Kr. Zamość. Münzschatz, mehr als 113 Münzen, davon 113 fassbar, Schlussmünze Clodius Albinus (193-194), RIC IV, lib. (Gładysz-Juścińska, Juściński 2010, 50 Fot. 7-8; 52 Fot. 9; 53 Fot. 10; 59 Fot. 14; Bursche 1999, 119-125).

23. Skoromochy Duże, Gem. Grabowiec, Kr. Zamość. Vermutlich Münzschatz, 3 Münzen, Schlussmünze D Faustina Filia (161-176), Rom, RIC M Aur 676.

24. Spiczyn, Gem. loco, Kr. Łęczna, Fpl. 53. Siedlung der Przeworsk-Kultur, verstreuter Münzschatz; 48 Münzen, Schlussmünzen D Commodus (Crispina) (180-183), Rom, BMC RE IV 695 Nr. 36 und D Macrinus (217-218), Antiochia, BMC RE V 507 Nr. 79 (Zugehörigkeit der letztgenannten zum Schatz unsicher Paszkiewicz 2011).

25. Strzyżów (??), Gem. Horodło, Kr. Hrubieszów. Vermutlich verstreuter Münzschatz, 10 Münzen, Schlussmünze D Commodus (schlecht erhalten), Rom (ca 176) (unpubliziert).

26. Swaryczów, Gem. Komarów-Osada, Kr. Zamość. Münzschatz im kleinen Tongefäß, über 100 Münzen, davon 95 fassbar, Schlussmünze D Pertinax (193), Rom, RIC la.

27. Szczepiatyn, Gem. Ulhówek Kr. Tomaszów Lubelski. Münzschatz, über 300 silberne römische Münzen.

28. Terebiniec, Gem. Werbkowice, Kr. Hrubieszów. Münzschatz, über 100 Münzen, davon 3 fassbar, Schlussmünze D Hadrian (117-138), Rom.

29. Tokary, Gem. Turobin, Kr. Biłgoraj. Münzschatz, über 700 Münzen, davon 433 fassbar, Schlussmünze D Septimius Severus (193-194), Rom, RIC 24.

30. Tuczapy, Gem. Mircze, Kr. Hrubieszów. Münzschatz, über 100 Münzen (Mitkowa-Szubert 1991, 179).

31. Tyszowce - Umgebung, Gem. loco, Kr. Tomaszów Lubelski. Münzschatz (?), im Wald „im Radius von ca. 3 km von der Stadt”, in zwei Konzentrationen gefunden; Schlussmünze D Marc Aurel (175-176), Rom, RIC III 326 bzw. 349 (Dymowski 2008, 59-60; Ders. 2011, 225-226 Nr. Mp92).

32. Uher, Gem. und Kr. Chełm, Münzschatz (?) von mehreren Münzen.

33. Walinna, Gem. Komarówka Podlaska, Kr. Radzyń. Münschatz, „Gefäß mit großer Menge von Münzen“, davon 2 fassbar, Schlussmünze D Marc Aurel (148-149).

34. Wierzchowiny, Gem. Siennica Różana, Kr. Krasnystaw, über 100 römische Münzen (Mitkowa-Szubert 1991, 179).

35. Wilków, Gem. Werbkowice, Kr. Hrubieszów. Münzschatz, über 150 Münzen, davon 97 fassbar, Schlussmünze D Pertinax (193), Rom, RIC 4 a.

36. Wojcieszków, Gem. und Kr. Łuków. Münzschatz, über 100 Münzen, davon 2 fassbar, Schlussmünze D Lucilla (164-180). 
37. Wytyczno, Gem. Urszulin, Kr. Włodawa, Fpl. 110/253 (AZP 73-88). Münzschatz, über 100 Münzen (TIR 2002, 353 Nr. 876).

38. Żulice, Gem. Telatyn, Kr. Tomaszów Lubelski. Münzschatz, über 1000 Münzen, davon 416 fassbar, Schlussmünze D Lucilla (164-169), Rom, RIC 788, BMC 325 (Mielniczuk 1997, 261-295; Feduszka 1999; Paszkiewicz 1999).

\section{LITERATURVERZECHNIS}

Bagińska J., Banasiewicz E., Niedźwiedź J., Taras H.

2000 Badania na wielokulturowym stanowisku $2 w$ Podlodowie, Kr. Tomaszów Lubelski, Archeologia Polski Środkowowschodniej 5, p. 75-79.

Banasiewicz E.

1994 Sprawozdanie $z$ prac sondażowych na cmentarzysku kultury przeworskiej $w$ Podlodowie stan. 2, Gem. Easzczów, Sprawozdania z badań archeologicznych w województwie zamojskim w 1993 roku, Zamość, p. 37-39.

1997a Zespót zabytków z grobu kultury przeworskiej odkryty w Górze Grabowiec, woj. zamojskie, Archeologia Polski Środkowowschodniej 2, p. 277-279.

1997b Kultura przeworska na południowo-zachodnim skraju Wyżyny Wotyńskiej (w obecnych granicach Polski), [in:] Kultura przeworska 3, J. Gurba, A. Kokowski (eds.), Lublin, p. 117-140.

1990 Sprawozdanie $z$ prac ratowniczych na stan. $4 \mathrm{w}$ kol. Husynne, Sprawozdania z badań terenowych w województwie zamojskim w 1990 roku, Zamość, p. 36-38.

1999 Sprawozdanie $z$ prac ratowniczych na st. 4 w kol. Husynne, Sprawozdania z badań terenowych w województwie zamojskim w 1999 roku, Zamość, p. 36-38.

Biborski M., Ilkjær J.

2006 Die Schwerter. Illerup Ådal, Jutland Archaeological Society Publications 25(11), Moesgård.

Bienia M.

2003 Czasy prehistoryczne, [in:] Pótnocna Lubelszczyzna od pradziejów po okres nowożytny, E. Banasiewicz-Szykuła (ed.), Lublin, p. 23-72.

Bochnak T., Opielowska-Nowak Z.

2017 Zubowice, pow. zamojski, stan. 1 - brazowa situla z grobu kultury przeworskiej świadectwem kontaktów wzdtuż tzw. „szlaku bastarniańskiego”?, Materiały i Sprawozdania Rzeszowskiego Ośrodka Archeologicznego 38, p. 155-184.

Bursche A.

1999 Znane $i$ nieznane znaleziska denarów rzymskich z ziem polskich, Wiadomości Numizmatyczne 43(1-2), p. 115-135.

Castagne C., Kokowski A.

1989 Osada kultury przeworskiej w Drażgowie, stan. 3, gm. Utęż, woj. lubelskie, Sprawozdania z badań terenowych Katedry Archeologii UMCS w 1989 roku, Lublin, p. 24-25.

Castagne F., Kokowski A.

1989 Dalsze badania ratownicze w Drażgowie, stan. 1, gm. Utęż, woj. lubelskie, Sprawozdania z badań terenowych Katedry Archeologii UMCS w 1989 roku, Lublin, p. 32-34. 
Chotyński A.

1908 Zabytki przedhistoryczne nad rzeczka Chodelka, pow. puławski, gub. Lubelska, Światowit 8(1907), p. 64-64.

1911 Zabytki przedhistoryczne z Dratowa, Trzcińca, Żmijowisk $i$ innych wsi w powiecie Puławskim, Światowit 9, p. 47-60.

Czopek S.

1980 Dobre, gm. Wilków, woj. lubelskie, Sprawozdania z badań terenowych Zakładu Archeologii UMCS w 1980 roku, Lublin, p. 6-8.

Dąbrowska T.

1962 Przyczynki do znajomości skarbu monet rzymskich ze Swaryczowa, pow. Tomaszów Lubelski, Wiadomości Archeologiczne 28, p. 396-397.

1963a Cmentarzysko z okresu rzymskiego w Jakubowicach, pow. Kraśnik, Wiadomości Archeologiczne 29, p. 316-318.

1963b Znaleziska zokresu rzymskiego z Opola Lubelskiego, Wiadomości Archeologiczne 29, p. 318-319.

2008 Młodszy okres przedrzymski na Mazowszu $i$ zachodnim Podlasiu. Zarys kulturowo-chronologiczny, Materiały Starożytne i Wczesnośredniowieczne 7, Warszawa.

Drewko M.

1957 Sprawozdanie $z$ badań przeprowadzonych $w 1955$ r. na wczesnośredniowiecznym cmentarzysku kurhanowym we wsi Lipsko, pow. zamojski, Sprawozdania Archeologiczne 3, p. 165-167.

Dymowski A.

2008 Najnowsze znaleziska monet rzymskich z Lubelszczyzny i Podkarpacia, Lubelskie Wiadomości Numizmatyczne 14, p. 36-68.

2011 Znaleziska monet rzymskich $z$ terenu Polski rejestrowane $w$ pierwszych latach XXI wieku. Aspekty źródtoznawcze, Zielona Góra.

Fedorowicz W.

1984 Druga część skarbu denarów rzymskich z Romanowa, Wiadomości Numizmatyczne 28(1-2), p. 55-83.

2003 Trzecia część skarbu denarów rzymskich z Romanowa, woj. lubelskie, Wiadomości Numizmatyczne 47, p. 5-47.

Feduszka J.

1999 Zamojska część skarbu monet rzymskich z Żulic, Wiadomości Numizmatyczne 43, p. $69-98$

Florek M., Libera J.

2006 Zabytki archeologiczne pochodzqce z odkryć przypadkowych z pótnocnej części Kotliny Sandomierskiej, Materiały i Sprawozdania Rzeszowskiego Ośrodka Archeologicznego 27, p. 101-117.

Gajewski L.

1980 Zniszczony grób ciałopalny z późnego okresu wpływów rzymskich we Wronowicach-Paprzycy, woj. zamojskie, Wiadomości Archeologiczne 45, p. 248-249.

1999 Grób ciałopalny kultury przeworskiej w miejscowości Brzeźce, gm. Stężyca, pow. Ryki, woj. lubelskie [in:] Kultura Przeworska 4, A. Kokowski (ed.), Lublin, p. 159-161.

Gajewski L., Gurba J., Kokowski A.

1981 Zubowice. Civilisation de Przeworsk dans la region de Lublin, Inventaria Archaeologica Pologne, Fasc. 45, PL 274. 
Gawrysiak L.

2004 Województwo lubelskie (mapa), Lublin.

Gładysz M., Kokowski A.

1997 Badania ratownicze wschodniej części stanowiska $n r 2$ w Drażgowie (Kolonii), woj. lubelskie, Archeologia Polski Środkowowschodniej 2, p. 124-126.

Gładysz-Juścińska M.

2009 Importowana fibula brazowa zdobiona emalia znaleziona w Woli Uhruskiej, pow. włodawski, woj. lubelskie, [in:] Hereditas praeteriti. Additamenta archaeologica et historica dedicata Ioanni Gurba Octogesimo Anno Nascendi, H. Taras, A. Zakościelna (eds.), Lublin, p. 315-320.

Gładysz-Juścińska M., Juściński M.

2010 Skarby z okresu rzymskiego $i$ wędrówek ludów, [in:] Skarby Lubelszczyzny, E. Banasiewicz-Szykuła (ed.), Skarby z przeszłości 11, Lublin, p. 37-72.

Gurba J.

1954 Cmentarzysko lateńsko-rzymskie w Masowie, pow. Garwolin, badane w 1953 roku, Wiadomości Archeologiczne 20, p. 303.

1958 Grób wojownika z późnego okresu lateńskiego z Masowa w pow. Garwolińskim, Przegląd Archeologiczny 20, p. 326-331.

Gurba J., Ślusarski Z.

1964-1965 Bogato wyposażony grób z III wieku z Podlodowa $w$ pow. tomaszowskolubelskim, Przegląd Archeologiczny 17, p. 202-207.

Haisig M.

1950 Znalezisko rzymskich denarów ze wsi Zubowice, pow. Tomaszów Lubelski, Sprawozdania P.M.A. 3, p. 93-108.

Juściński M.

2003a Der erste „Bauerhof” der Przeworsk-Kultur, [in:] Die Vandalen - die Könige, die Eliten, die Krieger, die Handwerker, A. Kokowski, Chr. Leiber (eds.), Holzminden, p. 305-310.

2003b Siedlungen der Przeworsk-Kultur oder - wie die Vandalen gewohnt haben, Vernissage 9, p. 50-53.

2003b Tarkawica, Ldkr. Lubartów, Woi. lubelskie, Fdst. 5, [in:] Die Vandalen - die Könige, die Eliten, die Krieger, die Handwerker, A. Kokowski, Chr. Leiber (eds.), Holzminden, p. 485.

2004a Pierwsza „zagroda“kultury przeworskiej. Tarkawica, pow. Lubartów, woj. lubelskie, stan. 5, [in:] Wandalowie - strażnicy bursztynowego szlaku, J. Andrzejowski, A. Kokowski, Chr. Leiber (eds.), Lublin - Warszawa, p. 86-89.

2004b Tarkawica, pow. lubartowski, woj. lubelskie, stan. 5, [in:] Wandalowie-strażnicy bursztynowego szlaku, J. Andrzejowski, A. Kokowski, Chr. Leiber (eds.), Lublin - Warszawa, p. 327.

2008 Tarkawica, st. 5 - osada kultury przeworskiej ze środkowego okresu rzymskiego na Lubelszczyźnie (Polska), [in:] Barbarská sídliště. Chronologické, ekonomické a historické aspekty jejich vývoje ve svĕtle nových archeologických výzkumů, E. Droberjar, B. Komóroczy, D. Vachůtova (eds.), Brno, p. 327-344.

2009 Ostrogi z Gródka nad Bugiem, [in:] Hereditas praeteriti. Additamenta archaeologica et historica dedicata Ioanni Gurba Octogesimo Anno Nascendi, H. Taras, A. Zakościelna (eds.), Lublin, p. 321-325.

Kieferling G.

2002 Zabytki z mtodszego okresu przedrzymskiego oraz z okresu rzymskiego z terenów 
Podola $i$ Wotynia w zbiorach Muzeum Archeologicznego w Krakowie. AnnowolaBiata - Dobrostany - Iwachnowice - Kapuścince - Krystynopol - Euczka Przewodów - Rudki, Materiały Archeologiczne 33, p. 25-52.

Kloss A.

1991 Badania archeologiczne $w$ Zemborzycach-Dabrowie, woj. lubelskie, $w$ latach 1984-1985, Studia i Materiały Lubelskie 13, p. 7-12.

Kokowski A.

1985a Monety antyczne na Lubelszczyźnie, Wiadomości Numizmatyczne 28, p. 27-54, (1984).

1985b Lubelszczyzna w pierwszych wiekach naszej ery w świetle importów rzymskich, Rocznik Lubelski 22/24 (1981-1982), p.159-171.

1985c Die Feuerstahlwerkzeuge der Przeworsk-Kultur, [in:] Mémoires Archéologiques, Lublin, p. 109-127.

1989 Wielokulturowe stanowisko 2 w Drażgowie, gm. Utęż, woj. lubelskie, [in:] Sprawozdania z badań terenowych Katedry Archeologii UMCS w 1989 roku, Lublin, p. 29-32.

1990 Trzeci sezon badań stanowiska $n r 1$ w Drażgowie, woj. lubelskie, [in:] Sprawozdania z badań terenowych Katedry Archeologii UMCS w 1990 roku. Lublin, p. 26-29.

1991 Lubelszczyzna $w$ młodszym okresie przedrzymskim $i w$ okresie rzymskim, Lublin.

1994a Ostroga z cmentarzyska kultury przeworskiej w Opoce, [in:] Kultura przeworska 2, J. Gurba, A. Kokowski (ed.), Lublin, p. 167-169.

1994b Bemerkungen zu Schildbuckeln des Typs Jahn 8 (Ilkjoer Typ 5a-5b), [in:] Beiträge zu römischer und barbarischer Bewaffnung in den ersten vier nachchristlichen Jahrhunderten, C. von Carnap-Bornheim (ed.), Lublin - Marburg, p. 369-376.

1995 Problemy badania dziejów kultury przeworskiej, [in:] Kultura przeworska 1, J. Gurba, A. Kokowski (eds.), Lublin, p. 15-36.

1997 Schlossbeschläge und Schlüssel im Barbaricum in der Römischen Kaiserzeit und der frühen Völkerwanderungszeit (Klassifizierung - Verbreitung - Chronologie), [in:] Klasyfikacje zabytków archeologicznych 2, Z. Woźniak (ed.), Lublin, (1999).

1999a „Prowincja”kultury przeworskiej w młodszym okresie przedrzymskim nad dolnym Wieprzem, [in:] COMHLAN. Studia $z$ archeologii okresu przedrzymskiego $i$ rzymskiego w Europie Środkowej dedykowane Teresie Dabrowskiej w 65. rocznice urodzin, J. Andrzejowski (ed.), Warszawa, p. 203-216.

1999b Vorschlag zur relativen Chronologie der südöstlichen Kulturen des „Gotenkreises” (Die Forschungsergebnisse zur Masłomęcz-Gruppe in Polen), [in:] Die Sîntana de Mureş-Černjachov-Kultur. Akten des Internationalen Kolloquiums in Caputh vom 20. bis 24. Oktober 1995, G. Fuchs-Gomolka (ed.), Kolloquien zur Vor- und Frühgeschichte 2, Bonn, p. 179-209.

1999c Archeologia Gotów, Goci w Kotlinie Hrubieszowskiej, Lublin.

1999d Die Mastomęcz-Gruppe. Ihre Chronologie und Beziehungen innerhalb des gotischen Kulturkreises - ein Beispiel für den kulturellen Wandel der Goten im Verlauf ihrer Wanderungen, Bericht der Römisch-Germanischen Kommission 78, p. 641-833, (1997).

2001a Dzieje badań okresu rzymskiego w Kotlinie Hrubieszowskiej, [in:] Rzymskie dzieje Kotliny Hrubieszowskiej, Skarby z Przeszłości III, Lublin, p. 19-53, 71-83.

2001b Przyczynek do badań nad skandynawskimi oddziatywaniami na uzbrojenie wojowników kultury przeworskiej w okresie rzymskim, [in:] Superiores Barbari. 
Ksiega pamiatkowa ku czci Profesora Kazimierza Godtowskiego, R. MadydaLegutko, T. Bochnak (eds.), Kraków, p. 203-214.

2004 Wola Skromowska, pow. lubartowski, woj. lubelskie, [in:] Wandalowie-strażnicy bursztynowego szlaku, J. Andrzejowski, A. Kokowski, Chr. Leiber (eds.), Lublin - Warszawa, p. 315.

2005 Dwie „bitwy” o Kotlinę Hrubieszowska u schyłku starożytności, Wykład Inauguracyjny, Zamość.

2006 Starożytna Polska. Od trzeciego wieku przed Chrystusem do schytku starożytności, Warszawa.

2007 Goci - od Skandzy do Campi Gothorum (od Skandynawii do Pótwyspu Iberyjskiego), Warszawa.

2008 Dvi bytvy za Hrubeshivs'ku Kotlovynu na skhylku starozhytnosti (Дві битви за Грубешівську Котловину на схилку старожитності). Archeolohični Doslidžennja L'vivs'koho Universitetu 10, p. 60-91, (2007).

2009 Kontinuität und Diskontinuität der Besiedlung in der jüngeren vorrömischen Eisenzeit und in der römischen Kaiserzeit am Beispiel des Hrubieszów-Beckens, Přehled Výzkumů 50, p. 181-212.

Kokowski A., Kuśnierz J.

2003 Zubowice, Lkr. Zamość, Woi. lubelskie. Urnengrab in einem bronzenen Eimer, [in:] Die Vandalen - die Könige, die Eliten, die Krieger, die Handwerker, A. Kokowski, Chr. Leiber (eds.), Holzminden, p. 439.

Kokowski A., Kuśnierz J., Urbański A.

1997 Grób wojownika kultury przeworskiej ze Swaryczowa w woj. zamojskim, [in:] Kultura Przeworska 3, A. Kokowski (ed.), Lublin, p. 141-150.

2003 Swaryczów, Ldkr. Zamość, Woi. lubelskie. Brandgrab eines Kriegers, [in:] Die Vandalen - die Könige, die Eliten, die Krieger, die Handwerker, A. Kokowski, Chr. Leiber (eds.), Holzminden, p. 442.

2004 Swaryczów, pow. zamojski, woj. lubelskie, [in:] Wandalowie - strażnicy bursztynowego szlaku, J. Andrzejowski, A. Kokowski, Chr. Leiber (eds.), Lublin - Warszawa, p. 319.

Kokowski A., Kutyłowski A.

1987 Cmentarzysko z okresu wpływów rzymskich w Woli Skromowskiej, woj. lubelskie, Wiadomości Archeologiczne 68, p. 55-72, (1983).

Kokowski A., Łuczkiewicz P.

2002 Pikule - ein Opferplatz (?) aus der jüngeren vorrömischen Eisenzeit, [in:] Die Bewaffnung der Germanen und ihrer Nachbarn in den letzten Jahrhunderten vor Christi Geburt. Tagungsmaterialien aus Nałęczów, 23-25.09.1999, C. von Carnap-Bornheim, J. Ilkjær, A. Kokowski, P. Łuczkiewicz (eds.), Lublin, p. 147162.

Kokowski A., Maleev J.B.

1999 Nowe materiaty do katalogu zapinek typu Almgren II-43, [in:] Kultura Przeworska 4, A. Kokowski (ed.), Lublin, p. 175-180.

Kokowski A., Machul C., Rogatko J.

1988 Drą̇gów Kolonia, gm. Utę̇̇, woj. lubelskie, stan. 1, [in:] Sprawozdania z badań terenowych Katedry Archeologii UMCS w 1988 roku, Lublin, p. 11-13.

Kokowski A., Reszczyńska A., Roman E.

1997 Badania ratownicze na wielokulturowym stanowisku nr 1 w Drażgowie (Kolonii), woj. lubelskie, Archeologia Polski Środkowowschodniej II, p. 95-97. 
Kozak D.N.

1984 Pševors'ka kul'tura u Verchn'omu Podnistrov’ji ji Zachidnomu Pobužži, Kyjiv.

Kunisz A.

1972 Trzy skarby denarów rzymskim z Lubelszczyzny, Wiadomości Numizmatyczne 26, p. 91-118.

Kuśnierz J.

2005 Nieznana kolekcja zabytków z młodszego okresu przedrzymskiego, okresu rzymskiego $i$ wędrówek ludów z Topornicy stanowiska 21 i 22, [in:] Europa Barbarica. Ćwierć wieku archeologii w Masłomęczu, P. Łuczkiewicz, M. GładyszJuścińska, M. Juściński, B. Niezabitowska, S. Sadowski (eds.), Monumenta Studia Gothica IV, Lublin, p. 233-248.

Łuczkiewicz P.

2006 Perespa-kolejne cmentarzysko z okresu rzymskiego ze wschodniej Lubelszczyzny?, Wiadomości Archeologiczne 58, p. 390-394.

2008a Sobieszyn, Fdst. 14, Kr. Ryki, Wojw. lubelskie. Eine Siedlung der PrzeworskKultur aus jüngeren vorrömischen Eisenzeit und der frührömischen Kaiserzeit in Ostpolen, [in:] Barbarská sídliště. Chronologické, ekonomické a historické aspekty jejich vývoje ve světle nových archeologických výzkumů, E. Droberjar, B. Komóroczy, D. Vachůtova (eds.), Brno, p. 259-278.

2008b Osada kultury przeworskiej z młodszego okresu przedrzymskiego i okresu rzymskiego $w$ Sobieszynie, pow. rycki, stan. 14. Sprawozdanie z badań prowadzonych $w$ 2005 i 2007 r., Archeologia Polski Środkowowschodniej 10, p. 53-66.

2015 Sobieszyn, stan. 1. Zniszczone cmentarzysko kultury przeworskiej z młodszego okresu przedrzymskiego i rzymskiego, [in:] Ubi tribus facibus fluenta Vistulae fluminis ebibuntur. Jerzy Okulicz-Kozaryn in Memoriat, B. Kontny (ed.), Barbaricum 11, Warszawa, p. 383-400.

2016 Osadnictwo z mtodszego okresu przedrzymskiego, [in:] Horodysko. Od epoki kamienia do wczesnego średniowiecza. Badania 2004-2005, T. Dzieńkowski (ed.), Lublin, p. 144-195.

Mielniczuk B.

1997 Skarb rzymskich denarów I-II w.n.e. z Żulic, województwo zamojskie w Muzeum Okręowym w Koszalinie, Koszalińskie Zeszyty Muzealne 21, p. 261-295.

Mitkowa-Szubert K.

1991 Znaleziska monet antycznych poświadczone $w$ dokumentacji Państwowego Muzeum Archeologicznego w Warszawie, Wiadomości Numizmatyczne 35(3-4), p. 177.

Niedźwiadek R.

2017 Przeszłość Hajdowa-Zadębia, Felina i Tatar w świetle odkryć archeologicznych, [in:] Lublin historia dzielnic w 700. rocznicę lokacji miasta, J. Chachaj, H. Mącik, D. Szulc (eds.), Lublin, p. 265-276.

Niedźwiadkowie A.R.

1997 Badania ratowniczo-weryfikacyjne na osadzie wielokulturowej w Dabrowie $w$ Lublinie, Archeologia Polski Środkowowschodniej II, p. 136-141.

1998 Wyniki badań wykopaliskowych na osadzie wielokulturowej w Lublinie Dabrowie, stan. 19, Archeologia Polski Środkowowschodniej III, p. 141-147.

Niewęgłowski A.

1982 Cmentarzysko kultury przeworskiej z okresu rzymskiego w Gościeradowie, gm. loco, woj. Tarnobrzeg, Sprawozdania Archeologiczne 33, p. 61-98. 
Niezabitowska B.

2004 Nowe znaleziska fibul oczkowatych z terenu Polski południowo-wschodniej, [in:] Europa Barbarica. Ćwierć wieku archeologii w Masłomęczu, P. Łuczkiewicz, M. Gładysz-Juścińska, M. Juścński, B. Niezabitowska, S. Sadowski (eds.), Monumenta Studia Gothica IV, Lublin, p. 489-496.

Niezabitowska-Wiśniewska B.

2016 Osadnictwo zokresu rzymskiego, [in:] Horodysko. Od epoki kamienia do wczesnego średniowiecza. Badania 2004-2005, T. Dzieńkowski (ed.), Lublin, p. 196-223.

2017 Zapinki typu Husynne z Lubelszczyzny, [in:] Orbis Barbarorum. Studia ad archaeologiam germanorum et baltorum temporibus Imperii Romani pertinentia Adalberto Nowakowski dedicata (= Monumenta Archaeologica Barbarica. Series Gemina VI), J. Andrzejowski, C. von Carnap-Bornheim, A. Cieśliński, B. Kontny (eds.), Warszawa - Schleswig, p. 475-493.

2018 Puławy-Wtostowice. Wielokulturowe stanowisko z zachodniej Lubelszczyzny, Lublin.

Nosek S.

1948 Zabytki kultury wenedzkiej z Lubelszczyzny, Annales Uniwersitatis Mariae Curie Skłodowska, Sec. F, III, p. 215-229.

Paszkiewicz B.

1999 Jeszcze dwa fragmenty skarbu monet rzymskich $z$ Żulic, Wiadomości Numizmatyczne 43, p. 99-114.

2011 Spiczyn, gm. loco, pow. tęczyński, Wiadomości Numizmatyczne 55/1-2, p. 192-199. Polańska M.

1999 Z najdawniejszych dziejów, [in:] Lublin i okolice w badaniach archeologicznych, E. Banasiewicz (ed.), Lublin, p. 5-14.

2000 Pierwszy sezon badań wielokulturowego stanowiska 7 w Garbatówce Kolonii, pow. Eęczna, Archeologia Polski Środkowowschodniej 5, p. 16-24.

2001 Wyniki drugiego sezonu badań wielokulturowego stanowiska 7 w Garbatówce Kolonii, pow. Eęczna, Archeologia Polski Środkowowschodniej 6, p. 32-37.

Reszczyńska A.

2005 Grot żelazny $z$ okresu wptywów rzymskich z miejscowości Łaczki-Pawłówek, gm. Borzechów, powiat lubelski, [in:] Europa Barbarica. Ćwierć wieku archeologii $w$ Masłomęczu, P. Łuczkiewicz, M. Gładysz-Juścińska, M. Juściński, B. Niezabitowska, S. Sadowski (eds.), Monumenta Studia Gothica IV, Lublin, p. 387-390.

Sadowski S.

2006 Rozpoznawcze badania wykopaliskowe na wielokulturowym stanowisku $\mathrm{nr}$ 1 w Zubowicach, pow. zamojski, Archeologia Polski Środkowowschodniej 8, p. $78-83$.

Stasiak M.

1994 Ceramika z cmentarzyska kultury przeworskiej w Opoce, [in:] Kultura przeworska 2, J. Gurba, A. Kokowski (eds.), Lublin.

Stasiak-Cyran M.

1999 Nowe materiały do poznania kultury przeworskiej na Lubelszczyźnie, [in:] Kultura Przeworska 4, A. Kokowski (ed.), Lublin, p. 163-169, (1998).

2003a Podlodów, Ldkr. Tomaszów Lubelski, Woi. lubelskie, Brandgrab eines Kriegers. [in:] Die Vandalen - die Könige, die Eliten, die Krieger, die Handwerker, A. Kokowski, Chr. Leiber (eds.), Holzminden, p. 442-443. 
2003b Masów, Ldkr. Ryki, Woi. lubelskie, [in:] Die Vandalen - die Könige, die Eliten, die Krieger, die Handwerker, A. Kokowski, Chr. Leiber (eds.), Holzminden, p. 443-446.

2003c Opoka, Ldkr. Puławy, woi. lubelskie, [in:] Die Vandalen - die Könige, die Eliten, die Krieger, die Handwerker, A. Kokowski, Chr. Leiber (eds.), Holzminden, p. 447-449.

2004a Masów, pow. rycki, woj. lubelskie, [in:] Wandalowie - strażnicy bursztynowego szlaku, J. Andrzejowski, A. Kokowski, Chr. Leiber (eds.), Lublin - Warszawa, p. 289, 291, 301-302, 323, 330, 345.

2004b Opoka, pow. puławski, woj. lubelskie, [in:] Wandalowie - strażnicy bursztynowego szlaku, J. Andrzejowski, A. Kokowski, Chr. Leiber (eds.), Lublin - Warszawa, p. 299, 302-303, 320-321, 323.

2004c Podlodów, pow. tomaszowski, woj. lubelskie, [in:] Wandalowie - strażnicy bursztynowego szlaku, J. Andrzejowski, A. Kokowski, Chr. Leiber (eds.), Lublin - Warszawa, p. 320.

2008 A settlement in Nieszawa Kolonia and the problem of the end of the Przeworsk Culture in the western Lublin region, [in:] The Turbulent Epoch. New materials from the Late Roman Period and Migration Period II, B. NiezabitowskaWiśniewska, M. Juściński, P. Łuczkiewicz, S. Sadowski (eds.), Monumenta Studia Gothica 5, Lublin, p. 309-328.

2016a Nieszawa Kolonia stanowisko 5, powiat Opole Lubelskie. Interdyscyplinarna monografia osady z okresu rzymskiego, Lublin.

2016b Archeologia na drogach - nowe dane do badań nad kultura przeworska na Lubelszczyźnie, [in:] Drogi Lubelszczyzny. Odkrycia i badania archeologiczne, E. Banasiewicz-Szykuła (ed.), Skarby przeszłości 17, Lublin, p. 161-170.

2018a Grób wojownika z Bliskowic, pow. kraśnicki-nowe dane do studiów nad rozwojem kultury przeworskiej na Lubelszczyźnie, [in:] Studia Barbarica. Profesorowi Andrzejowi Kokowskiemu w 65 rocznice urodzin, v. I, B. NiezabitowskaWiśniewska, P. Łuczkiewicz, S. Sadowski, M. Stasiak-Cyran, M. Erdrich (eds.), Lublin, p. 266-280.

2018b Próba rekonstrukcji modelu diety mieszkańców Lubelszczyzny $w$ pierwszych wiekach naszej ery, [in:] Dziedzictwo kulinarne w kontekstach tradycyjnych $i$ wspótczesnych, J. Abramowicz, M. Tymochowicz (eds.), Lublin, p. 43-51.

Szarek-Waszkowska E.

1971 Cmentarzysko kultury przeworskiej w miejscowości Opoka, pow. Puławy, Studia i Materiały Lubelskie 5, p. 79-187.

Śmiszko M.

1932 Kultury wczesnego okresu epoki Cesarstwa Rzymskiego w Małopolsce Wschodniej, Lwów.

TIR

2002 Tabula Imperii Romani M 34 - Kraków, P. Kaczanowski, U. Margos (eds.), Kraków.

Tkaczyk J.

2017 Archeologia Czechowa. [in:] Lublin historia dzielnic w 700. rocznice lokacji miasta, J. Chachaj, H. Mącik, D. Szulc (eds.), Lublin, p. 157-161.

Uzarowiczowa A.

1970 Nowe znaleziska archeologiczne z powiatu Puławy, Wiadomości Archeologiczne 35, p. 422-423. 
Vojnarovs'kyj V.

2013 Dobrynivci I- čynbars’kyj kompleks černjachivs'koji kul'tury na Bukovyni, L'viv. Wichrowski Z.

1997 Cmentarzysko kultury przeworskiej w Kraśniku - Piaskach, stan. 2, Archeologia Polski Środkowowschodniej 2, p. 113-116.

Wichrowski Z.

1998 Badania archeologiczne na cmentarzysku kultury przeworskiej w KraśnikuPiaskach, stan. 2, woj. lubelskie, Archeologia Polski Środkowowschodniej III, 104-109.

1999 Badania ratownicze na cmentarzysku kultury przeworskiej $w$ Kraśniku-Piaskach, stan. 2, woj. lubelskie, Archeologia Polski Środkowowschodniej 4, p. 119-122.

2000 Badania ratownicze na cmentarzysku kultury przeworskiej $w$ Kraśniku-Piaskach, stan. 2, woj. lubelskie, Archeologia Polski Środkowowschodniej 5, p. 96-104.

2003 Kraśnik-Piaski, Ldkr. Kraśnik, Woi. lubelskie, Fdst. 2, [in:] Die Vandalen - die Könige, die Eliten, die Krieger, die Handwerker, A. Kokowski, Chr. Leiber (eds.), Holzminden, p. 434-435.

2004 Kraśnik Piaski, pow. kraśnicki, woj. lubelskie, stan. 2, [in:] Wandalowie strażnicy bursztynowego szlaku, J. Andrzejowski, A. Kokowski, Chr. Leiber (eds.), Lublin - Warszawa, p. 318-319, 321.

Witkowski A.

2016 Wyniki badań szczatków ryb $z$ osady $z$ okresu rzymskiego $w$ Nieszawie Kolonii, stanowisko 5, pow. Opole Lubelskie, [in:] M. Stasiak-Cyran, Nieszawa Kolonia stanowisko 5, powiat Opole Lubelskie. Interdyscyplinarna monografia osady $z$

Żórawski S. okresu rzymskiego, Lublin, p. 288-290.

2017 Dzielnice Stawin, Stawinek $i$ Szerokie w świetle badań archeologicznych, [in:] Lublin historia dzielnic $w$ 700. rocznice lokacji miasta, J. Chachaj, H. Mącik, D. Szulc (eds.), Lublin, p. 384-391.

Address of the Author

\section{Andrzej Kokowski}

Institute of Archaeology

Maria Curie-Sklodowska University

Plac Marii Curie-Skłodowskiej 5

20-031 Lublin, Poland

berig1@gazeta.pl

ORCID ID: 0000-0001-7275-4395 